\title{
Roads to Development: Experimental Evidence from Urban Road Pavement*
}

\author{
Marco Gonzalez-Navarro \\ UC Berkeley ${ }^{\dagger}$
}

\author{
Climent Quintana-Domeque \\ Universitat d'Alacant ${ }^{\ddagger}$
}

First Draft

February 16, 2010

\begin{abstract}
Urban peripheries in many developing country cities lack basic local public goods like pavement, water, sewerage and electricity. We estimate the impacts of slum infrastructure upgrading using an experiment in urban road pavement provision in Mexico. Our findings show that homes in streets that were paved increased their value between 13 and $24 \%$. Households living in streets that were paved obtained more credit, had higher per capita expenditures, increased motor vehicle ownership and were more likely to have made home improvements. The rate of return to road pavement is estimated to be $2 \%$ without considering externalities, but raises to $55 \%$ once externalities are accounted for. We also present a model to understand the experimental estimates. Increases in consumption are more strongly correlated with increases in housing value than reductions in transportation costs, suggesting that the wealth effect generated by the road pavement was a stronger driver of consumption than the reduction in transportation costs.
\end{abstract}

JEL: C92, C93, H41, O15, O12

${ }^{*}$ We would like to thank Anne Case, Angus Deaton, Alan Krueger, David Lee, Adriana Lleras-Muney, Sam Schulhofer-Wohl, Christina Paxson, and Cecilia Rouse for their help and advice in this research project. The collaboration of the Acayucan 2005-2007 and 2008-2010 Municipal administrations is gratefully acknowledged. We also recognize the effort of José Luis Palma, Luz Uribe and Monica González at INSAD who were in charge of the survey. Financial aid from Princeton University, Princeton Woodrow Wilson Scholars, Princeton Industrial Relations Section, Princeton Research Program in Development Studies, Robert Wood Johnson Scholars in Health Policy Research Program, Universitat d'Alacant, the Lincoln Institute of Land Policy and the Spanish Ministry of Science and Innovation (ECO 2008-05721/ECON) is gratefully acknowledged. Any errors contained in the paper are our own.

${ }^{\dagger} 50$ University Hall, MC 7360 Berkeley, CA 94720. Email: marcog@berkeley.edu

${ }_{\ddagger}^{\ddagger}$ Departament de Fonaments de l’Anàlisi Econòmica, Universitat d'Alacant, Sant Vicent del Raspeig, 03690 Alacant, Spain. Email: climent@ua.es 


\section{Introduction}

Developing countries are urbanizing at a much more rapid pace than was experienced by currently developed economies (Henderson, 2002; UN-Habitat, 2003). Rapid population growth in cities has generated a widespread lack of urban infrastructure, especially in the outskirts of cities. Because it is precisely in the outskirts of urban areas where welfare indicators are worse (Napier, 2009), it is important to understand what the effects of urban infrastructure are. In particular, it is crucial for policy makers to know if investments in urban infrastructure can be an effective tool in poverty alleviation, in a context in which public funds must compete with cash transfer programs - such as Progresa.

Roads have been proposed for a long time as poverty reduction tools (Jalan and Ravallion, 2002). However, there is little convincing evidence that road paving affects social outcomes (Van de Walle, 2002). The main endogeneity challenge with any study focusing on impacts of infrastructure is that a simple comparison of places with and without infrastructure in observational data can be misleading (Duflo and Pande, 2007). Paraphrasing Van de Walle (2002) "The general point here is that unless road placement is truly random - which seems most unlikely - simple comparisons of outcome indicators in places with roads versus without them can be very deceptive." Our work is unique in that it is the first to solve the problem of endogenous road infrastructure placement by using random assignment. When treatment is randomly assigned, the treatment is independent of other sources of variation, and any bias is balanced across treatment and controls.

We study the effects of an experiment in urban infrastructure provision in Mexico. The experimental design consisted of randomly selecting from a pre-approved set of street projects (defined as contiguous sets of unpaved city blocks connecting to the city's pavement grid) a subset to be treated with road pavement. Randomization of urban infrastructure provision is assessed through a household baseline survey (pre-intervention) and the evaluation of the effects of urban infrastructure provision is done by means of a household follow up survey and a business census (post-intervention). 
At the household level, we find that road pavement increased property values by around $15 \%$ according to professional appraisals, and by around $24 \%$ according to homeowners. While collateral-based credit from the private sector more than doubled in terms of number of loans and size, we find no response in other forms of credit, such as non collateral based, or from family and friends. The provision of road pavement appears to have incentivized households to make home improvements and buy materials for home improvements. Moreover, the household head was substantially more likely to use motorized transport to go to work as a result of the paving of the road, and households in general increased by $50 \%$ their vehicle ownership. Plans to outmigrate for work reasons were reduced as a result of the infrastructure. Lastly, monthly per capita expenditure is estimated to have increased by around $10 \%$, and the treated households increased the number of durable goods they possess.

At the neighborhood level, we find that out and immigration were not affected by the treatment, nor the characteristics of migrants. The business census evidence suggests that the road pavement had no impact on business opportunities in treated areas. Number of business units were unchanged, number of employees and firm profits did not vary with access to pavement.

Interestingly, we find experimental effects at the household but not at the business level. Although in a different context, these findings are consistent with Haughwout (2002), who concludes that the principal beneficiaries of infrastructure investment are property owners, not firms. ${ }^{1}$

In an approach reminiscent of Jacoby (2000), in which properties along paved roads are understood as assets whose price equals the net present value of the benefits they provide, we provide a cost benefit analysis of road pavement by comparing the costs of the roads to the increase in property values they generated. The sum of values of properties along paved

\footnotetext{
${ }^{1}$ His findings for the USA show that one-standard deviation increase in a city's infrastructure stock raises the value of an acre of city land by between $\$ 11,000$ and $\$ 22,000$ (an elasticity of 0.11 and 0.23 ). In contrast, the elasticity of productivity with respect to infrastructure is 0.038 .
} 
roads increased by slightly more than the cost of the pavement, generating a positive return of $2 \%$. However, when externalities on unpaved road properties are taken into account, the estimated return to roads increases to $55 \%$.

There is a large non-experimental macro literature on returns to infrastructure, mostly based on cross-regional and cross-country data (Antle, 1983; Aschauer, 1989; Holtz-Eakin, 1992; Kneller et al., 1999; Canning and Bennathan, 2000; Briceño; Esfahani and Ramirez, 2003; Estache, and Shafik, 2004; Fan and Chan-Kang, 2005), which estimates returns to public infrastructure between 0 and 200\%. ${ }^{2}$ However, as already pointed out by Gramlich (1994), it is very difficult to obtain economic measures of rates of return to public infrastructure and econometric estimates of productivity impacts. Our study contributes to this macro-growth literature on infrastructure by providing an experimental estimate of the rate of return to road pavement in a developing country. This is particularly important given that public spending on infrastructure in developing countries averaged $9 \%$ of government spending (World Bank, 1994) and 15\% to $20 \%$ of the World Bank's lending portfolio is targeted towards transport investments (Khandker, 2009).

Despite the widespread belief that infrastructure is integral to development, evidence on how investment in physical infrastructure affects individual wellbeing remains limited, as pointed out by World Bank (1994), Jimenez (1995) and Dinkelman (2008). By focusing on how treated households respond to urban road pavement, we can better understand the impact of public infrastructure on individual wellbeing. Not only this, we are also able to investigate some potential mechanisms by which urban road pavement affects household behavior. Hence, we also contribute to the infrastructure literature from a microeconomic point of view, and to the growing literature studying the impact of public infrastructure in the context of a developing country (Lokshin and Yemtsov, 2005; Van de Walle and Mu, 2007; Michaels, 2008).

\footnotetext{
${ }^{2}$ In his review of the literature, Holtz-Eakin (1992) concludes that the evidence from state-level and region-level US data indicates a 0 elasticity of private output or productivity with respect to state or local government capital. However, Kneller et al. (1999) finds that across 22 OECD countries productive government spending has a social rate of return of between 10 and $20 \%$.
} 
The structure of the paper is as follows. Section 2 describes the experimental design. Section 3 offers a description of the experiment streets in 2006, before the intervention. Section 4 discusses the identification strategy and provides some testable implications. In Section 5 we present evidence that the randomization produced a balanced sample between treatment and control groups in terms of observables, and present our experimental estimates. Section 6 discusses some potential mechanisms to understand the experimental estimates and provides some evidence on them. In Section 7 we explore the role of externalities and present a cost-benefit analysis. Finally, Section 8 concludes. 


\section{Experimental Design}

\subsection{Institutional Context}

Acayucan is a municipality in the southern part of the state of Veracruz, in eastern Mexico. In Table 1 we present some descriptive statistics from the entire city, column (1), and from the experiment streets, columns (2) and (3). According to the 2005 short Census (Conteo), the municipality has a population of 79,459 , with the city accounting for about 50,000 . The average altitude is 100 meters above sea level, with tropical climate. The sex ratio is 0.89 males for every female. ${ }^{3} 58 \%$ of the population lacks health insurance. Of those aged 15 and more, $9 \%$ are illiterate. School enrollment is $94 \%$ among adolescents aged 12-14.

Regarding household level variables, electricity is enjoyed by almost everyone with $98 \%$ of homes having electricity in their property. Tap water is less common: 16\% of private inhabited dwellings report not having access to piped water in their lot or home. In terms of assets, $81 \%$ of homes have a refrigerator, $55 \%$ have a washing machine, and $14 \%$ have computers.

Interestingly, the descriptive statistics from the 2006 baseline survey are close to those of the 2005 short Census, with the exception of computer ownership and number of rooms in the house, which are smaller for inhabitants from our survey. Although census tracts with streets that are part of the experiment have worse indicators than census tracts in the downtown area of the city, there are many areas that were not part of the experiment with even worse socioeconomic indicators. This highlights the fact that although the experiment took place in parts of the city that are relatively poor, they did not contain the poorest households, which tend to live in scarcely populated areas with many vacant lots, where the municipal government was not yet interested in providing urban road infrastructure. This aspect must be taken into account when assessing the external validity of our estimates.

\footnotetext{
${ }^{3}$ Grech et al (2003) have documented a falling male to female ratio in all of Mexico, but well above one. The only explanation we have encountered in the literature for low male to female sex ratios such as the one in Acayucan is the existence of male migrant labor (Bean, King, and Passel, 1980).
} 
Municipal governments in Mexico have as their main responsibilities garbage collection, paying for public street illumination, providing local public safety, regulating businesses, tending to public gardens, and providing and maintaining public infrastructure including sewerage, road pavement, and sidewalks. Each three-year administration has freedom to choose what it will focus its budget on.

Mexico's government obtains its funds mainly from a national VAT, a national income tax, and oil proceeds from the state-run oil company. These funds are shared by the three orders of government: Federal, States and Municipalities. Hence, funding of the municipal government comes mainly from transfers from the Federal and State Government. A significant portion of these transfers is conditional on being spent on things like infrastructure. Local sources of revenue (mainly the urban property tax) account for less than $10 \%$ of the total municipality budget.

\subsection{The Experiment}

The 2005-2007 Acayucan administration put forth as its priority providing pavement in city areas lacking these services. However, the infrastructure needs of the city were much larger than what could be provided for with the municipality budget. Under these circumstances, we proposed a randomized evaluation of their urban road pavement infrastructure investments.

Throughout the city, there are many streets without pavement. The administration was interested in upgrading those with higher population densities, and left for the future areas that were not yet heavily populated. The mayor and the public works personnel provided us with a set of 56 "street projects" they were interested in upgrading throughout the city. The administration was responsible for selecting and defining those projects. The street projects consisted of sets of contiguous city blocks that connected to the existing city pavement grid. One condition for being part of the experiment was for the street not to be paved. Once it became part of the experiment, the city determined if the tap water or sewerage lines would 
be replaced or upgraded.

Given that the administration would not be able to provide infrastructure to the 56 street projects, council members and the mayor voted to let us use random assignment to choose which roads to pave within the set of interest to them. The administration understood the randomization as a fair and transparent way to assign the infrastructure. The randomization also provides a credible strategy to identify the benefits of such a policy because it manages to overcome the selection bias, a major concern in the infrastructure literature.

\subsubsection{Street Projects}

A street project consists of a contiguous set of unpaved urban blocks to be provided pavement connecting them to the grid of paved streets. More specifically, the street projects the administration defined were characterized by lack of pavement, but were characterized by being highly populated. Figure 1 shows the location of experiment areas throughout the city.

Acayucan is an urban area with a development pattern typical of Mexico and other Latin American countries. The central part of the city has public services including electricity, sewerage, tap water, pavement, public transportation, and garbage collection. As distance from the city center increases, public infrastructure and services become less common. Pavement is one of them.

\subsubsection{Treatment}

One important challenge for the randomization was the many sources of uncertainty the Municipal government would face during the course of the infrastructure construction. These included volatile government income and input cost fluctuations. Two factors could slow down construction: one was unforeseen weather - construction crews could not perform some important tasks on rainy days -, the second was delays in water pipe installation by the State Water Authority, which is not under direct supervision of the Municipality. 
Given that the municipal government is free to choose its infrastructure program, the municipality decided there was no need to announce to the population the existence of this study. Moreover, the questionnaire did not mention that its objective was to measure the effects of infrastructure and field workers were trained to not mention this to respondents. Hence, changes in behavior among the treatment group (Hawthorne effects) and among the control group (John Henry effects) were minimized.

By March 2009, 17 of the streets in the treatment group had been completely treated, five were in process but unfinished, and six had not been pursued. Table 2 lists all the projects assigned to the treatment group, the infrastructure they got and the date in which this was completed. Out of the six projects that were not pursued, four were due to technical difficulties: Either a rocky bottom that required dynamite to place the sewer line, when the municipality did not have the technical capacity for this, or the proximity to a river that meant that the project would have to be done jointly with the State Water Authority and was left for the future.

Although the weather and some technical difficulties prevented the administration from finishing all the infrastructure projects in time for the follow-up survey, they did fulfill the requirement of not treating the projects randomly assigned to the control group. This is important because under one-sided non-compliance, the Bloom (1984) result tells us how to use the IV formula to estimate the average effect of the treatment on the treated.

Finally, it is worth mentioning that the administration did not agree to paving streets in a random order, mainly because there are efficiencies when paving streets that are near one another: by moving machinery around from one street project to another and traveling a very short distance; establishing a common point close to various street projects to distribute construction material; and having constant supervision of workers. 


\subsection{Sources of Information}

In our experiment, the unit of randomization is the street project, though the main unit of analysis is the household within each street. Information on households was collected through the Acayucan Standards of Living Survey (ASLS, Encuesta de Condiciones de Vida y Opciones Económicas en Acayucan). The survey contains two rounds: a baseline (2006) and a follow-up (2009) conducted during the second half of February and the beginning of March. Both rounds were conducted during the same months with the intention of minimizing seasonality effects. The target population of the ASLS consisted of all private households or businesses located on the street projects that were part of the experiment.

We decided to conduct a baseline survey because of three main reasons. First, a baseline survey provides an opportunity to check that randomization was conducted appropriately. This is particularly important in our context because when randomization is done at the cluster level instead of individually, there is a non-negligible probability that the randomization produces groups with different average characteristics (Bloom, 2006). Second, collecting baseline data offers an opportunity to test and refine data collection procedures. Finally, a baseline survey provides information on lagged outcomes that may generate more precise estimates of the effects of the treatment on outcomes by including them in a regression of the final outcome on the treatment variable and a constant.

We also obtained information on business units through a very short business census in 2006 and 2009 and home value assessments made by a real estate agent.

\subsubsection{Household Surveys}

The survey firm created a sampling frame from all inhabited residential dwellings found in experiment streets in early 2006. As recognized by Deaton (1997), the use of out-dated or otherwise inaccurate sampling frames is an important source of error in survey estimates. The sampling procedure was clustered sampling: From the list of dwellings in each cluster we randomly chose a pre-specified fraction of them to be interviewed. 
Given the uncertainty about the total number of projects the municipality would be able to conclude by the time of the follow-up survey, and since we did not have any prior about having different sample variances of the outcome means in the treatment and control groups, we decided to sample with a higher intensity in the intent-to-treat group ( $70 \%$ of dwellings) than in the control group (50\% of dwellings). ${ }^{4}$

Notice that some dwellings would contain more than one household (defined as a group of one or more people who live in the same house and share food expenditures). The procedure in case of multiple households per dwelling was to interview all of them. It is worth noting that neither quota sampling nor substitution of non-responding households or individuals (whether refusals or non-contacts) were permitted at any stage.

The household questionnaire collects detailed information for each individual in the household (ie. age, sex, etc.) and characteristics at the household level (ie. wall material, electricity availability, etc.). Both household and individual questions were answered by a reference person who was targeted to be either the household head or the spouse/partner of the head. In over $95 \%$ of cases the respondent was the household head or the spouse as intended. If the household head or the spouse were not going to be available in a second visit, but a knowledgeable adult was willing to participate, the interview took place.

Survey weights (or expansions factors) represent the inverse of the probability that a dwelling or household is included in the sample. They are constructed taking into account the proportion of households that we attempted to interview in each cluster and cluster specific non-response. In the construction of the weights non response is assumed to be random: it simply inflates the weight given to households in a project that were successfully interviewed. The response rate in the baseline survey was $94 \%$.

In order to compare nominal variables between the follow-up (2009) and the baseline (2006) survey, the cumulative inflation between 2006-2009, 14.68\%, must be taken into account.

\footnotetext{
${ }^{4}$ Duflo et al. (2006) and List et al. (2010) offer a detailed discussion on optimal size arrangements.
} 


\subsubsection{Business Census}

A very short business census was applied to all business units with their main entrance on the street project in 2006 and 2009. Mobile business units were excluded from analysis (for example a seller on a motorcycle, or a water distributor going around on a truck). The supervisors of each survey team were in charge of locating all business units on their street project and administering the questionnaire. The questions included the type of business, years of operation, employees, total sales, expenditures, changes in profits, and whether the business unit is located in a house, a special purpose commercial locale, or on the street.

\subsubsection{Housing Value Assessments}

Finally, the other source of data in the study was the housing value assessments produced by a real estate agent. Having only one real estate agent perform all the assessments has the positive feature that heterogeneity of assessment practices, which require a lot of subjective decision-making, was minimized. The real estate agent was asked to visit one out of every

two successfully interviewed homes and to assess the market value of the house in 2006 and 2009. In each year, the assessments were performed once the household survey fieldwork was completed. 


\section{Baseline Descriptive Statistics}

This section offers a detailed picture of the study areas in 2006. Table 3 provides descriptive statistics. The survey obtained information from 1,231 households, with an average and median of 4 members, suggesting a nuclear family rather than an extensive household with multiple generations. The survey sample is almost exclusively of mixed Mexican race, given that only $3 \%$ of individuals speak an indigenous language. Individuals aged 15 and over have a median of 8 years of schooling (mean of 7.5 years) and $88 \%$ of them have ever attended school. Lack of schooling is mostly concentrated among the elderly. $88 \%$ of individuals aged 5 and over declare to be literate - defined as being able to read and write a note in Spanish.

Home ownership is relatively high: $83 \%$ if households declare to be owners of the property they live on. However, only $71 \%$ of homeowners have a title of property. Indeed, some homeowners even declared to have acquired the property by invading it. The survey asked for an estimate of property value, and although non-response for this question is quite high, Gonzalez-Navarro and Quintana-Domeque (2009) have shown that the probability of nonresponse is uncorrelated with professionally appraised values of these same properties. The median house value estimate is 100,000 2006 Mexican pesos (14,000 PPP-adjusted 2005 US dollars). Houses in the sample are relatively simple, with a median of 2 rooms (mean of 2.3 rooms), $93 \%$ of the homes with cement floor (or hard-floor) and $92 \%$ with cement walls. Cement roof is not the norm, given that only $37 \%$ of homes have it. Asbestos or metal sheets were by far the most common form of roofing. $41 \%$ of homes have the bathroom located outside the house. $25 \%$ of households use wood or charcoal as cooking fuel. In households that cook with wood the kitchen is typically under a roof outside the main structure.

In terms of labor, $51 \%$ of the 4,099 individuals aged 8 and over worked the previous

week. A person is defined as working if he or she engaged in any income generating activity or worked without pay in the family business or farm. Among those who worked, the median number of days worked was 6 and the average was 5.5 days. Work is usually 8 hours per day. Multiplying days worked by the number of hours worked per day provides a measure 
of weekly hours worked. With a median of 48 and an average of 46.5 hours worked last week, part-time employment does not seem to play an important role. Average monthly labor income is 2,752 pesos, with a median of 2,000 pesos (280 PPP adjusted 2005 US dollars). Our estimated rate of unemployment (excluding students, housewives, the elderly and anyone not looking for work) is around $6 \%$, which compares to the $3.5 \%$ unemployment rate for Mexico as a whole in the first quarter of 2006. This suggests that the inhabitants of the city's outer neighborhoods do not seem to experience the degree of high joblessness encountered in other urban contexts (Magruder, 2009).

In the consumption panel of Table 3 we can see that household expenditure is on average 3,268 pesos, with a median of 2,800 pesos. Dividing monthly household expenditure by the number of family members provides a measure of per capita expenditure, which is on average 931 pesos with a median of 750 pesos (around 100 PPP-adjusted 2005 US dollars per month). The median per capita expenditure is slightly higher than the 2 dollar a day ${ }^{5}$ poverty line (Banerjee and Duflo, 2007). In terms of durable goods, $12 \%$ of households have an automobile, and $8 \%$ have a pick up truck. The median household does not have either. In terms of other durable goods, $79 \%$ of households have a refrigerator, $51 \%$ have a washing machine, $38 \%$ have a video player, $20 \%$ have a microwave oven, $10 \%$ have a personal computer, and $6 \%$ have air conditioning. Television and radio ownership were not asked because other surveys have showed that they have been almost universally adopted in Mexican households. Participation in government welfare programs, such as ProgresaOportunidades, DIF food aid, is positive in $7 \%$ of households.

The panel on public services shows that the distance to the nearest paved street is on average 1.4 blocks. Street blocks in Acayucan vary in size but are roughly 200 meters long. $78 \%$ of households have tap water in their lot. During the course of the fieldwork, we learned that some households do have a tap water line to their property but do not use it because they have not opened an account with the water company. These families either fetch their

\footnotetext{
${ }^{5}$ The 2 dollar a day poverty line was for 1985, which is 2.92 dollars in 2005 .
} 
water from a neighbor, or use a water well. $87 \%$ of homes have a sewerage line connected to the city sewerage system. Electricity was available in practically all homes (98\%). Regarding garbage collection, although the service is free and supposedly universal, only $58 \%$ of homes declared to have refuse collection services. Those without collection service either burn their refuse or take it to a street where the garbage is actually collected. $22 \%$ of homes experienced a flooding of their home in the past year. In terms of public safety, $11 \%$ of homes experienced a burglary in the past 12 months, and $62 \%$ declare to feel safe walking in their street at night.

The credit panel shows that in 2006 17\% of households had a bank account, and $10 \%$ had a credit card. Use of collateral based credit, such as mortgages and private bank loans was positive for $2.6 \%$ of individuals aged 18 and over, whereas uncollateralized credit was positive for $0.4 \%$ of individuals (Electronic and furniture store credit, credit card, automobile loans, etc.) Credit from informal sources, such as friends and family, was relatively uncommon, as only 0.4 and $0.7 \%$ of individuals reported using credit from these sources in the past year.

In terms of schooling, $87 \%$ of children aged 5-17 were reported to be able to read and write a note in Spanish. 91\% of children aged 5-17 were enrolled in school, and 21\% reported missing at least 1 school day in the past month.

The Table also inquires about expectations. $45 \%$ of individuals in the sample had plans to out migrate for work reasons. Regarding the satisfaction of living in Acayucan, the average and the median on a 4 point increasing scale was 3: satisfied. When asked about 13 different kinds of home improvements performed in the past 6 months, the average number of improvements was 0.45 and the median was 0 . Only $5 \%$ of households declared to have opened a business in the past year. $64 \%$ of those new businesses were located at home.

Satisfaction with the three levels of government was obtained on a 4 point increasing scale. State and Federal government had an average score of 2.55, whereas the Local government had a lower average score of 2.35. The median was "not satisfied" (2) for the local government. Meanwhile, the median score for the State and Federal governments was "satisfied" (3). 
In the baseline round, 250 business units were located and successfully interviewed in the study areas. We present summary statistics from the business census for employment (firm size), sales, expenditures, and estimated profits. We trim the sample by $5 \%$ from above and below in terms of profit rank to eliminate the influence of extreme outliers. The median firm in the study areas has 1 worker (who is usually the owner) and an average of 1.66 workers. The largest firm had 10 workers. Median sales were 2,000 pesos, median expenditures were 1,050 pesos and median profits were 800 pesos per month (PPP equivalent \$112). The averages are larger but a similar picture emerges. All measures are suggestive of very small businesses. The most common business is a small shop (tiendita) selling goods like milk, tortillas, beer, sodas, potato chips, canned goods, candy and snacks (50\% of units). In $84 \%$ of cases, the business is located in the house of the owner. The business census revealed that less than $15 \%$ of adults work in business units located in the neighborhoods under study. These neighborhoods are thus primarily for housing people whose work is located either in the downtown areas of the city or in ranches/farms located around the city. The little commerce that exists is mainly providing basic foods to neighbors of these areas. 


\section{Identification and Testable Implications}

The identification framework contained in this section draws on Duflo et al. (2006) and Angrist and Pischke (2009).

\subsection{ATET: Average Treatment Effect on the Treated}

In our analysis, the treatment is defined at the street level (being paved or not) and it is described by a binary random variable, $D_{i}=\{0,1\}$. The outcome of interest is denoted by $Y_{i}$. The question is whether $Y_{i}$ is affected by the treatment. To address this question, we use the potential outcomes framework (Rubin, 1974). Hence, for any individual or household living in a street there are two potential outcome variables: $Y_{i}^{0}$ is the outcome of an individual or household had his street not been paved, irrespective of whether it actually was, and $Y_{i}^{1}$ is the individual's or household's outcome if his street is paved. We would like to know the difference between $Y_{i}^{1}$ and $Y_{i}^{0}$, which can be said to be the causal effect of paving the street for an individual or household $i$. The observed outcome, $Y_{i}^{0}$, can be written in terms of potential outcomes as

$$
Y_{i}=Y_{i}^{0}+\left(Y_{i}^{1}-Y_{i}^{0}\right) \cdot D_{i}
$$

where $Y_{i}^{1}-Y_{i}^{0}$ is the causal effect of pavement for an individual or household. Because we never see both potential outcomes for any one individual or household, we must learn about the effects of pavement by comparing the average outcome of those whose streets were and were not paved. The comparison of average outcome conditional on treatment status is formally linked to the average causal effect by the equation

$$
\underbrace{E\left[Y_{i} \mid D_{i}=1\right]-E\left[Y_{i} \mid D_{i}=0\right]}_{\text {Comparison }}=\underbrace{E\left[Y_{i}^{1} \mid D_{i}=1\right]-E\left[Y_{i}^{0} \mid D_{i}=1\right]}_{\text {ATET }}+\underbrace{E\left[Y_{i}^{0} \mid D_{i}=1\right]-E\left[Y_{i}^{0} \mid D_{i}=0\right]}_{S B}
$$


The term $E\left[Y_{i}^{1} \mid D_{i}=1\right]-E\left[Y_{i}^{0} \mid D_{i}=1\right]=E\left[Y_{i}^{1}-Y_{i}^{0} \mid D_{i}=1\right]$ is the average causal effect of treatment on those who were treated (ATET). The term $E\left[Y_{i}^{0} \mid D_{i}=1\right]-E\left[Y_{i}^{0} \mid D_{i}=0\right]$ is called selection bias (SB). This term is the difference in average $Y_{i}^{0}$ between those who were and those who were not treated. Random assignment of $D_{i}$ solves the selection problem because random assignment makes $D_{i}$ mean independent of potential outcomes:

$$
E\left[Y_{i}^{0} \mid D_{i}=1\right]-E\left[Y_{i}^{0} \mid D_{i}=0\right]=E\left[Y_{i}^{0}\right]-E\left[Y_{i}^{0}\right]=0
$$

Hence, under random assignment of $D_{i}$ :

$$
\underbrace{E\left[Y_{i} \mid D_{i}=1\right]-E\left[Y_{i} \mid D_{i}=0\right]}_{\text {Comparison }}=\underbrace{E\left[Y_{i}^{1}-Y_{i}^{0} \mid D_{i}=1\right]}_{A T E T}
$$

Let $Z_{i}$ be the random assignment to treatment versus no-treatment. In our experiment, $D_{i} \neq Z_{i}$. Although non-compliance can be in two-directions, in many randomized trials, such as job training programs (e.g., JTPA), only one-sided non-compliance occurs. On the one hand, participation is voluntarily among those randomly assigned to receive treatment, $D_{i}=$ $\{0,1\}$ if $Z_{i}=1$. On the other hand, no one in the control group has access to the experimental intervention, $D_{i}=0$ if $Z_{i}=0$. Since the group that receives (i.e. complies with) the assigned treatment is a self-selected subset of those offered treatment, comparison between those actually treated and the control group is misleading. The selection bias in this case is almost always positive; those who take advantage of randomly assigned economic interventions such as training programs tend to earn more anyway (Angrist and Pischke, 2009). 
In general, using IV in a randomized trial with one-sided non-compliance allows us to estimate the ATET, (Bloom, 1984). The IV estimate is obtained by regressing the outcome of interest on the treatment, where the latter is instrumented by assignment status ${ }^{6}$.

$$
E\left[Y_{i}^{1}-Y_{i}^{0} \mid D_{i}=1\right]=\frac{E\left[Y_{i} \mid Z_{i}=1\right]-E\left[Y_{i} \mid Z_{i}=0\right]}{E\left[D_{i} \mid Z_{i}=1\right]}
$$

In the first part of our experimental analysis we need to show that we can actually estimate the ATET. In other words, we need to offer evidence that randomization successfully balanced subjects' characteristics across the intent-to-treat (ITT) and control groups. To do that, we compare pretreatment (observable) characteristics $X_{i}$ across groups. If we do not find systematic differences in mean (observable) characteristics between the ITT and control groups before the intervention, the assignment to the ITT group is random, and hence we have a valid instrument to identify the $\mathrm{ATET}^{7}$. Hence, our first testable implication is the following:

Testable Implication 4.1 (ATET Identification: based on baseline characteristics) If the ITT and control groups have the same mean pre-treatment characteristics, the groups are balanced, and we have a valid instrument to identify the ATET. The ATET is identified if we cannot reject $H_{0}$ :

$$
\begin{aligned}
& H_{0}: E\left[X_{i} \mid Z_{i}=1\right]=E\left[X_{i} \mid Z_{i}=0\right] \\
& H_{1}: E\left[X_{i} \mid Z_{i}=1\right] \neq E\left[X_{i} \mid Z_{i}=0\right]
\end{aligned}
$$

We provide evidence supporting the identification of the ATET in Table 5 (Section 5). ${ }^{8}$

\footnotetext{
${ }^{6}$ Frölich and Blaise (2008) show that if additional control variables are included in the model, treated and compliers are not identical, and ATET $\neq$ LATE. They discuss several reasons for doing so. First, when the treatment is randomly assigned but the assignment probability differs between individuals. Second, nonresponse and attrition are universal problems of most randomized trials, particularly when one is interested in medium to long-term effects of a treatment. Third, when including additional covariates to separate direct from indirect effects. Finally, when the instrumental variable has not been randomly assigned and therefore might be confounded, unless we condition on several background characteristics. None of these scenarios apply to our case.

${ }^{7}$ The assumption being that if there are no mean differences in observable characteristics, there will be no mean differences in unobservable characteristics.

${ }^{8}$ The intention-to-treat effect (ITTE) is immediately identified by regressing the observed outcome of
} 


\subsection{ATE: Average Treatment Effect}

As discussed above, random assignment of $D_{i}$ solves the selection problem. Further, ATE=ATET:

$$
\underbrace{E\left[Y_{i} \mid D_{i}=1\right]-E\left[Y_{i} \mid D_{i}=0\right]}_{\text {Comparison }}=\underbrace{E\left[Y_{i}^{1}-Y_{i}^{0} \mid D_{i}=1\right]}_{A T E T}=\underbrace{E\left[Y_{i}^{1}-Y_{i}^{0}\right]}_{A T E}
$$

In words, under random assignment (and perfect compliance, $D_{i}=Z_{i}$ ), the average effect of treatment on the treated is the same as the average effect of the treatment on a random chosen individual-household.

With one-sided non-compliance, comparing OLS with IV estimates should give us the magnitude of the selection bias:

$\underbrace{E\left[Y_{i}^{0} \mid D_{i}=1\right]-E\left[Y_{i}^{0} \mid D_{i}=0\right]}_{S B}=\underbrace{E\left[Y_{i} \mid D_{i}=1\right]-E\left[Y_{i} \mid D_{i}=0\right]}_{O L S}-\underbrace{E\left[Y_{i}^{1} \mid D_{i}=1\right]-E\left[Y_{i}^{0} \mid D_{i}=1\right]}_{I V}$

In other words, since the experimental protocol is violated, we should expect to identify at most the ATET. However, in our randomized control trial clusters of individuals (streets) rather than independent individuals are randomly allocated to intervention groups: the outcome of interest occurs at the individual level whereas the randomization occurs at the cluster (street) level. Hence, in our case, one-sided non-compliance does not come from the fact that some individuals decided whether to participate in the program or not, but because the government could not comply in providing the randomly assigned treatment by the time we ran the follow-up survey or had not started. Hence, unless government non-compliance is related to both socio-economic characteristics of the place that could not be paved and those of the families living there, selection bias is much less likely to be a concern.

There are two testable implications to check whether selection bias (endogeneity) is a concern:

interest $Y$ on a constant and $Z$. However, in our case, this effect gives us the average causal effect of being randomly selected to be paved. Given that people did not know about their assignment status, the ITTE does not seem to provide meaningful estimates. 
Testable Implication 4.2 (ATE Identification 1: based on baseline characteristics) If the ITT-treated and the ITT-untreated groups have the same mean pre-treatment characteristics, the groups are balanced, and there is no selection on pre-treatment characteristics. There is no selection on pre-treatment characteristics if we cannot reject $H_{0}$ :

$$
\begin{aligned}
& H_{0}: E\left[X_{i} \mid D_{i}=1, Z_{i}=1\right]=E\left[X_{i} \mid D_{i}=0, Z_{i}=1\right] \\
& H_{1}: E\left[X_{i} \mid D_{i}=1, Z_{i}=1\right] \neq E\left[X_{i} \mid D_{i}=0, Z_{i}=1\right]
\end{aligned}
$$

Further, if we find that there is no selection on pre-treatment characteristics, we should not find statistically differences between OLS (ATE) and IV (ATET) estimates. This suggests testing the following implication:

Testable Implication 4.3 (ATE Identification 2: based on follow-up estimates) Let us write the following outcome and first-stage equations:

$$
\begin{aligned}
& Y_{i}=\alpha+\beta \cdot D_{i}+u_{i} \\
& D_{i}=\gamma+\pi \cdot Z_{i}+e_{i}
\end{aligned}
$$

where $D_{i}$ is the potentially endogenous treatment and $Z_{i}$ is a valid instrument, e.g., the random assignment to treatment. Then a test of the null hypothesis that $D_{i}$ is not correlated with $u_{i}$ is equivalent to a test of the hypothesis that $\rho$ equals zero in the following auxiliar regression

$$
Y_{i}=\alpha+\beta \cdot D_{i}+\rho \cdot \widehat{e}_{i}+u_{i}
$$

where $\widehat{e_{i}}$ represents the fitted residual from the first stage regression, i.e., $\widehat{e_{i}}=D_{i}-\widehat{\gamma_{O L S}}-$ $\widehat{\pi_{O L S}} \cdot Z_{i}$. The term $\widehat{e_{i}}$ comprises the potential endogenous component of $D_{i}$ that is related to $Y_{i}$, all exogenous influences being captured in $D_{i}$. Thus, the test of exogeneity would be the test of $H_{0}: \rho=0$. If we cannot reject $H_{0}$, exogeneity of $D_{i}$ cannot be rejected. 
In Table 5 (Section 5) we provide evidence that selection bias did not occur in our experiment (and Tables 8, 9 and 10 in section 5 show no differences in migration behavior among ITTtreated, ITT-untreated and control groups). Further, Table 6 (Section 5) suggests that there are no systematic differences between our OLS and IV estimates. Indeed, the Hausmanregression tests in Table 13 (Appendix) show that we cannot reject the equality of OLS and IV estimates. Hence, in our experiment, both ATET and ATE are identified.

Testable Implication 4.3 uses the Durbin-Wu-Hausman (DWH) test, a regression-based form of the Hausman test for the presence of systematic differences between OLS and IV estimates (Wooldridge, 2002; Cameron and Trivedi, 2009), that under independent homoskedastic standard errors turns out to be asymptotically equivalent to the original form of the Hausman test (Hausman 1978, 1983). The DWH test produces a robust test statistic (Davidson, 2000), even under heteorskedastic errors ${ }^{9}$. In general, this test lacks of power due to the low correlation of the instrument with the potentially endogeneous variable. However, this is not a problem in our case, since random assignment to treatment with one-sided non-compliance satisfies the relevance condition by construction.

\section{$5 \quad$ Experimental Analysis}

This section is divided into three subsections: baseline balance, experimental estimates and selective migration. The first two subsections focus only on households that were surveyed in 2006 and again in 2009. The third subsection shows that neither intensity of out-migration nor characteristics of out-migrants were affected by treatment.

Households interviewed in 2006 can be partitioned into two groups: those who stayed in the experimental areas and those that moved out between 2006 and 2009. Due to budgetary reasons, the survey only followed up on non-mover households. ${ }^{10}$ Although mover households

\footnotetext{
${ }^{9}$ The Hausman test is based on the assumption that $\widehat{\operatorname{Var}}\left(\widehat{\beta_{I V}}-\widehat{\beta_{O L S}}\right)=\widehat{\operatorname{Var}}\left(\widehat{\beta_{I V}}\right)-\widehat{\operatorname{Var}}\left(\widehat{\beta_{O L S}}\right)$, which is correct only if $\widehat{\beta_{O L S}}$ is the fully efficient estimator under the null hypothesis of exogeneity, an assumption that is valid only under the very strong assumption that model errors are independent and homoskedastic.

${ }^{10}$ If it were of interest in the future to interview mover households, this could be attempted by contacting
} 
were not contacted, we do have information about them from the 2006 ASLS that allow us to understand along which dimensions they were different from those who stayed.

Creating a panel data set of households creates important challenges for the survey that must be carefully dealt with. Given that the survey observation unit is the household, ${ }^{11}$ it naturally changes over time. For example, a household can be subdivided when a son or daughter marries and the dwelling now has two groups with separate meal expenditures. In order to deal with these issues, a module on household integration was added to the 2009 survey.

Field workers had maps with locations of dwellings interviewed in 2006. They approached the dwelling in 2009 with questionnaires that had a pre-filled section with identifying information about the household that was interviewed in 2006. If the head of the household was the same as in 2006, the households were matched. ${ }^{12}$ If there were additional households in the dwelling (new households or subdivisions), they were all interviewed, but were coded as new households (with no household counterpart in 2006). Matched households allow an analysis of changes within households over time.

In the second round of the ASLS we were able to measure how the infrastructure provision changed the composition of the neighbors that inhabit the road pavement projects. The characteristics of new neighbors were assessed in two ways. First, by interviewing new households living in dwellings vacated by mover households: if a dwelling that was surveyed in 2006 had a different household in 2009, the new household was interviewed (but had no household counterpart in 2006). The purpose of these surveys is to measure if neighbors attracted by the infrastructure have different characteristics than those who were already living there. However, not all new households come to live in pre-existing houses, some families build new houses upon arrival. To include them in our measurement, households the reference person each household was asked to provide in the 2006 ASLS.

${ }^{11} \mathrm{~A}$ household is defined as a group of one or more people who live in the same house and share food expenditures.

${ }^{12}$ The exception to this rule occurs if family members are the same, but now another member is declared to be the household head. 
living in all residential constructions built between 2006 and 2009 were also interviewed.

The matched data set thus contains three types of households: 1- Those interviewed in 2006 and 2009, 2- those interviewed in 2006 only that could not be followed because they out migrated, and 3- new households with information from the 2009 round only (which can be further subdivided into: new households replacing those that out migrated, households inhabiting new constructions, subdivisions of households from 2006, and new households that neither substituted mover households nor were part of the household in 2006).

Table 4 presents a summary of the interview results for the 2006 and 2009 matched data set. The baseline sampling frame was all inhabited residential structures with main entrance facing the proposed road pavement projects found in early 2006. Out of 1,275 inhabited residential structures selected for interview, completed interviews were obtained from 1,193 dwellings. The response rate was thus a very high 94\%. In those 1,193 dwellings, 1,231 household interviews were obtained, because in a few cases, there were 2 (and even 3 ) households living in the same property.

The 2009 survey was intended to follow up on the 1,231 households successfully interviewed in 2006. 900 follow-up households were successfully located and interviewed. In 56 cases the family was located but refused to participate in the survey, and in 271 cases the household had moved. The household was categorized as having moved if neighbors or new dwelling inhabitants had information that the previous family had moved out. This means the 2009 ASLS survey had a recontact rate of $73 \%$ of households interviewed in 2006 . The main reason for the low recontact rate was household out-migration.

In 2009, 183 new households were interviewed. 120 of the newly interviewed households were families living in the dwellings left by mover households (labeled "Substitution" in the Table). 27 families were interviewed in new inhabited residential constructions. 22 cases were family subdivisions; typically one of the sons got married, had a child, and created a new household in the same plot because food expenditure was not shared with the parents anymore. 14 cases were simply defined as new households and occurred whenever the 2006 
household was contacted, but now there was an additional family in the household. For example, if a room in the property was now rented out to another family. The 2009 ASLS round obtained a total of 1,083 completed surveys.

\subsection{Baseline Balance}

In order to test if ATET and ATE are identified, Table 5 presents average baseline characteristics for three different groups: ITT versus Control, Treated versus Untreated, and Treated (ITT \& treated) versus ITT \& untreated. Standard errors are calculated using the survey weights and clustering at the road pavement project level. ${ }^{13}$

The Table reports baseline characteristics by treatment status for 65 indicators of demographic characteristics, housing quality, credit, labor, consumption, public services, schooling of children, satisfaction with government, and business units characteristics. We find evidence of balanced characteristics across ITT and control groups before the intervention. Only in 2 out of 65 cases (3.1\%), the differences are statistically significant: income of men in the ITT group appears to be $16 \%$ higher than in the control group at the $10 \%$ significance level, and the probability of being sick last month is around $2 \%$ higher for the ITT group at the $5 \%$ significance level. Hence, we cannot reject $H_{0}$ of testable implication 5.1: ATET is identified.

Looking at the second group in Table 5, we find evidence of balanced characteristics across treated and untreated groups before the intervention. Only in 3 out of 65 cases (4.6\%), the differences are statistically significant: dwellings in the treated group are almost $11 \%$ more likely to have tap water connection in lot $(\mathrm{p}$-value $<0.1)$; gas delivery service appears to be $7.4 \%$ more common in treated streets ( $\mathrm{p}$-value $<0.01$ ); and male labor income in the treated group appears to be $21 \%$ higher than in the control group at the $10 \%$ significance level.

The findings regarding the second group suggest that both OLS and IV estimates should

\footnotetext{
${ }^{13}$ Following Deaton (2009), an alternative test of equality of means is a two sample $t$-test with unequal variances between groups using Welch's (1947) approximation. This alternative provides a solution to the Fisher-Behrens problem of testing the significance of the difference between the means of two normal populations with different variances. The standard errors using this alternative test were very similar.
} 
provide similar estimated effects. Indeed, the comparison of average characteristics for the third group (ITT treated versus ITT untreated) show that 8 out of 65 mean differences are statistically significant, suggesting that we cannot reject $H_{0}$ of testable implication 5.2: ATE appears to be identified. In the next subsection we report our experimental estimates and we provide a test for detecting systematic differences between OLS and IV estimates (ATE Identification 2).

\subsection{Experimental Estimates}

We present our main experimental estimates for different outcomes in Table 6. In the first two columns, we report OLS estimates without and with the lagged outcome variable as a regressor. Columns (3) and (4) report the corresponding IV estimates, where the treatment variable is instrumented with the treatment status assignment. Finally, the last column provides the mean of the outcome variable for the control group. Adding the lagged outcome variable as a control variable is standard in the impact evaluation literature (Duflo et al., 2006; Kling, Liebman, and Katz, 2007) in order to reduce the standard error on the coefficient of interest without biasing the estimate. All regressions include a constant term, use the survey weights and standard errors are clustered at the street project level.

The top panel in Table 6 focuses on housing indicators. The first thing to note is that the distance to the nearest paved street in terms of street blocks decreased. Around $95 \%$ of nonmover households owned their dwelling in 2009, and there was no significant difference across treatment groups. This suggests that home ownership was not affected by the treatment. The $\log$ home owner estimate of housing value did go up because of treatment. Treated households estimate an increase in housing value of 20-24 percentage points due to having the road where their home is located being connected to the pavement grid. According to the professional appraisal home values, the increase appears to be of $13-15 \%$.

As in many developing country contexts, Acayucan households improve and expand their house over time. Hence, home characteristics at any point in time provide a measure of 
cumulative investments in the house. We asses differences in housing quality by treatment group using a set of house quality indicators. ${ }^{14}$ However, in the short run, we find no evidence of changes in the overall housing stock characteristics, as measured by quality of flooring, walls and roofing, or number of rooms. Similarly, having a bathroom inside the house a good measure of housing quality in this context - is unchanged by treatment status in the short run. Nevertheless, we do find differences in the number of home improvements made in the last 6 months: households in paved streets appear to be involved in more home improvement, such as floor improvement, plumbing, electrical, toilets, remodeling, and AIR conditioning, than households in control streets. Also, they are more likely to have bought material for home improvement in the last 6 months.

Overall, the housing indicators suggest that people estimate the properties on paved roads to be worth about $22 \%$ more than without pavement, while the increase according to the real estate agent's home valuation is around 14\%. But in the short run, we found no differences in overall housing stock quality by treatment group. Given that the wealth of most families is concentrated in their house, an increase of this magnitude in the value of the household's main asset suggests that credit constraints should be relaxed as a result.

Interestingly, Table 6 shows that collateralized credit composed of mortgages and private bank loans increases with treatment status. In particular, individuals in treated street projects are more likely to have collateral based credit than individuals from untreated streets. Not only are more individuals using collateralized credit, the average credit size is around three-four times as large in treated than in untreated street projects. This suggests the road pavement increased the value of the households' main asset and relaxed some of the credit constraints treated households face. Indicators for the household having a credit card or a bank account do not show any effect of the intervention. Access to non-collateral credit (and its amount) does not seem to respond to the pavement intervention either. Also, credit

\footnotetext{
${ }^{14}$ Following Kling et al (2007)), for questions with multiple related outcomes, such as construction materials in the house, durable goods in the household and improvements to the house, we use a summary index of outcomes by adding up dummy variables.
} 
from family and friends is unaffected by treatment status (see Table 14 in the Appendix).

Looking at labor variables, there is some weak evidence of a labor supply increase due to the pavement intervention. More interestingly, are the results on labor market expectations and motor transport to work: first, households in treated streets are $7-11 \%$ less likely to have a member planning to migrate for work reasons than those in control ones; second, household heads in treated streets are more likely to use a motor transport to go to work. These findings suggest that investments in urban infrastructure may be a way for international migrant origin countries to hold on to their human resources. Results on satisfaction living in Acayucan was unchanged by paving of the street (see Table 14 in the Appendix).

In terms of consumption, our results suggest that paving the street was reflected in higher log household or per capita expenditures (PCE). The estimated differences in columns (2) and $(4)$ are $8 \%(\mathrm{p}$-value $<0.1)$ and $10 \%(\mathrm{p}$-value=0.103), respectively. These magnitudes are in line with Khandker et al (2009), who find an increase in household per capita consumption of $8-10 \%$ due to rural road improvement. Notice that the difference in PCE is not explained by higher household participation in government welfare programs.

There is stronger evidence that durable goods increased among treated households. Out of 7 durable goods, control households had an average of 2.4 goods. Treated households had around 0.21 more durable goods according to column (2) and 0.26 more goods according to column (4). Also, getting a paved street increases the utility of owning a vehicle because it is more likely to be able to reach the house, and be kept safer there. Together with the relaxing of the credit constraints, it makes sense for households to have responded to the treatment by acquiring a vehicle. This is reflected by the fact that our car-truck indicator is higher for households in treated streets.

Finally, pavement of the street did not make burglaries more likely in treated households. Actually, treated households were 10 percentage points more likely to feel safe while walking in their street at night than control households where only $62 \%$ felt safe walking in their street at night (see Table 14 in the Appendix). Notice also that the treatment generated no 
changes in school enrollment or school absences among children aged 5-17.

Business unit results are reported in Table 7. The top panel, labeled "intensive margin", presents regression results at the firm level. The results show that the average behavior of firms in the study area did not vary according to treatment. Neither number of employees, log sales, log expenditures, nor log profits varied by treatment status, either in the OLS or IV regressions. Although unreported in the Table, we obtained the same results for type of locale the business was in (formal independent, formal inside a residential lot, inside a house, or on the street). To determine if positive results were being masked by a temporary negative effect in streets recently paved (due to street blockages during construction) we performed tests of differences in sales, expenditures and profits according to an indicator for pavement taking place within the past 6 months and more than 6 months. We found no differences in outcomes for firms along this dimension.

The bottom panel in Table 7 reports tabulations for the sum of business units both in 2006 and 2009, to determine aggregate changes in economic outcomes by treatment status. Although the number of business units in ITT projects increased more than in control projects, both in absolute and in percentage terms, these differences were not borne out in terms of total employment. Similar results hold in a comparison of paved to unpaved areas. The business unit results suggest are somewhat unsurprising. Given the peripheral location of the street projects, pavement provision did not result in increased traffic (at least in the short run) and business units seemed to be serving the same clientele as before treatment.

\subsection{Selective Migration: Out-migrants and Immigrants}

Although a substantial amount of households were not interviewed in the follow up round due to the mobile nature of the population in the outer areas of the city, in this section we inquire whether movements in and out of the neighborhoods were affected by the paving of the roads. Table 8 provides evidence that the paving of roads did not generate any significant 
changes in in and out migration behavior of household. The dependent variable in the first two columns is a dummy for the household having outmigrated by 2009. The independent variable is an indicator of being in the intent to treat group in column 1, and being in the treated group in column 2. The control group had an average outmigration rate of $23 \%$. The small and insignificant estimated coefficients on the ITT and Treated regressors suggest the treated streets experienced an identical outmigration rate as the control ones. Columns 3 and 4 of the Table inquire if there was more immigration to treated than control streets. $17 \%$ of the 2009 sample had immigrated between 2006 and 2009. But this rate is no different in treated than in control streets.

\section{Understanding the Experimental Estimates}

This section explores the expected effects of road pavement from an economic perspective. In the first part, we perform a comparative statics exercise on the changes the road pavement is expected to bring about from the perspective of a standard household utility maximization model. In the second part, we test our model predictions by means of a regression analysis.

\subsection{A Simple Model}

We present a simple model that captures the two direct effects of road pavement, namely, the increase in the value of properties located along paved roads, and the reduction in transport costs. The household's utility $u$ depends on consumption and leisure. The utility maximization problem of the representative household is:

$$
\max _{c, l, k} u(c, l)
$$




$$
\text { subject to: } \begin{aligned}
(1-\tau) f(k, h)+r H & =c+\phi k \\
h+l & =1 \\
k & \leq \alpha H
\end{aligned}
$$

where $c$ denotes consumption, $l$ leisure, $h$ hours of work, $f$ is the production function of the household, $k$ is capital, $H$ is housing wealth, $r$ is the return to wealth, $\phi$ is the rental cost of capital, and $\alpha$ is the fraction of housing wealth that can be used as collateral. Transport costs are introduced as reducing output by a factor $\tau$. The utility function satisfies the following properties: $u_{c}>0$ and $u_{l}>0 ; u_{c c} \leq 0, u_{l l} \leq 0$, and $u_{c l} \geq 0$. The production function satisfies the following properties: $f_{k}>0$ and $f_{h}>0 ; f_{k k} \leq 0, f_{h h} \leq 0$, and $f_{k h} \geq 0$.

Under no credit constraints, the solution to this problem is well known. Here, we focus on the credit constrained case, i.e., $k=\alpha H$. From the first order conditions:

$$
\begin{gathered}
u_{l}=(1-\tau) f_{h} u_{c} \\
\lambda\left[(1-\tau) f_{k}-\phi\right]=\mu \\
(1-\tau) f(k, 1-l)+r H=c+\phi k \\
k=\alpha H
\end{gathered}
$$

where $\lambda>0$ and $\mu>0$. Taking the total differential from the equations above:

$$
\begin{gathered}
u_{l l} d l+u_{l c} d c=(1-\tau) f_{h}\left[u_{c c} d c+u_{c l} d l\right]+u_{c}\left[(1-\tau)\left(f_{h k} d k-f_{h h} d l\right)-f_{h} d \tau\right] \\
d \lambda\left[(1-\tau) f_{k}-\phi\right]+\lambda\left[(1-\tau) f_{k k} d k-f_{k} d \tau\right]=d \mu \\
(1-\tau) f_{k} d k-(1-\tau) f_{h} d l+r d H-F d \tau=d c+\phi d k \\
d k=\alpha d H
\end{gathered}
$$


Using equations $\lambda\left[(1-\tau) f_{k}-\phi\right]=\mu,(1),(3)$ and (4), we obtain:

$$
d c=\beta_{0} d H+\beta_{1} d \tau
$$

where

$$
\begin{gathered}
\beta_{0}=\left(\frac{\alpha(1-\tau)^{2} f_{h k} f_{h} u_{c}+\left[(1-\tau)\left(u_{c l} f_{h}-u_{c} f_{h h}\right)-u_{l l}\right]\left[\alpha \frac{\mu}{\lambda}+r\right]}{(1-\tau) f_{h}\left[u_{l c}-u_{c c}(1-\tau) f_{h}\right]+(1-\tau)\left(u_{c l} f_{h}-u_{c} f_{h h}\right)-u_{l l}}\right) \\
\beta_{1}=-\left(\frac{f_{h} u_{c}+\left[(1-\tau)\left(u_{c l} f_{h}-u_{c} f_{h h}\right)-u_{l l}\right] f}{(1-\tau) f_{h}\left[u_{l c}-u_{c c}(1-\tau) f_{h}\right]+(1-\tau)\left(u_{c l} f_{h}-u_{c} f_{h h}\right)-u_{l l}}\right)
\end{gathered}
$$

Given the utility and production function properties, and that we are focusing on the case where all constraints are binding, i.e., $\lambda>0$ and $\mu>0$, then

$$
\left.\frac{d c}{d H}\right|_{d \tau=0}=\beta_{0}>0
$$

That is, an increase in home value increases household consumption through two mechanisms: first by a wealth effect, and second by relaxing the household credit constraint and allowing the use of more capital.

$$
\left.\frac{d c}{d \tau}\right|_{d H=0}=\beta_{1}<0
$$

An increase in transport costs decreases consumption for two reasons: first by a substitution effect, making labor less productive and thus raising the relative price of consumption; secondly by an income effect, less income leads to a reduction of consumption. As mentioned above, for credit constrained households, an increase in home value leads to an increase in capital:

$$
\left.\frac{d k}{d H}\right|_{d \tau=0}=\alpha>0
$$

Analogously, we can derive the implications for household labor supply. However, the predictions for labor supply are ambiguous. A reduction in household transport costs increases the relative price of leisure, hence households will increase their labor supply. However, it also makes households wealthier, reducing their labor supply. Similarly, an increase in 
home valuation has two different effects. On the one hand, it makes households wealthier, decreasing their labor supply. On the other hand, it relaxes household credit constraints, which may lead to an increase in labor supply via a substitution effect.

\subsection{Empirical Specification and Results}

The measurement of transport costs poses a major difficulty for empirically investigating the

role of transportation in a wide range of economic activities. Although we do not observe household transport $\operatorname{costs} \tau$ directly, we observe the household distance to the nearest paved street $d$. In our context, we have reasons to think of household transport costs as depending positively on the distance to the nearest paved street.

The relationship between household transportation costs and distance to the nearest paved street is postulated to be

$$
\tau=\theta d+\epsilon
$$

where $\theta>0$ and $\epsilon$ contains any other determinant of transport costs. In general, the problem of using distance as a proxy for transport costs is that distance is related to other determinants that we do not observe, $\operatorname{cov}(d, \epsilon) \neq 0$. In such a case, the effect of distance cannot be disentangled from other potential factors affecting transport costs. However, the road pavement experiment changed the distance to the nearest paved street. Hence, we have:

$$
\Delta \tau=\theta \Delta d+\Delta \epsilon
$$

Assuming that the pavement experiment only affected transport costs through the reduction in distance, $\operatorname{cov}(\Delta d, \Delta \epsilon)=0$.

Equations (4), (5) and (6) suggest estimating the following empirical model:

$$
\Delta c=\beta_{0} \Delta H+\gamma_{1} \Delta d+\Delta u
$$




$$
\Delta k=\alpha \Delta H
$$

where $\gamma_{1}=\beta_{1} \theta$ and $\Delta u=\beta_{1} \Delta \epsilon$. If we know the sign of $\theta$ and assuming that $\operatorname{cov}(\Delta \tau, \Delta \epsilon)=$ 0 , we can identify the sign of $\beta_{1}$. However, the fact that we do not observe directly the change in transportation costs increases the residual variance. Hence, although we can identify the sign, we must be aware of the fact that, the higher is the increase in the residual variance, the lower will be the power to statistically detect the effect of the change in transportation cost on the change in consumption.

Including constants in the empirical model above we have the following final specification:

$$
\begin{gathered}
\Delta c=\kappa_{0}+\beta_{0} \Delta H+\gamma_{1} \Delta d+\vartheta \\
\Delta k=\kappa_{1}+\alpha \Delta H+\nu
\end{gathered}
$$

where $\vartheta \equiv \Delta \epsilon+\eta$ and $\nu$ are error terms that capture any random variation not accounted for in our model, such as measurement error in $c$ and $k$.

We estimate the model in two different ways. First, using OLS equation by equation. Second, we also estimate the two equations simultaneously by SUR in order to exploit the potential correlation between $\vartheta$ and $\nu$. More specifically, we perform SUR estimation in three different ways: (i) using weights, (ii) constraining the constants terms to be zero, and (iii) using cluster-bootstrapped standard errors.

Table 11 presents the estimates. As expected from our empirical model, we cannot reject either $\kappa_{0}=0$ or $\kappa_{1}=0$. More interestingly, $\beta_{0}$ and $\gamma_{1}$ are estimated to be positive and negative, respectively, though only the former is statistically significant. Given the point estimate of $\beta_{0}$, an increase in home value of 22,000 Pesos $\$$, which is the increase in the average home value due to pavement (15\% of the average home value in the control group, 145, 000 Pesos $\$)$, seems to translate into an increase of 44 Pesos $\$$ in monthly per capita consumption.

The fact that the estimated $\gamma_{1}$ is not statistically significant is not surprising. As discussed 
above, the change in distance only captures a small part of the change in transportation costs. The point estimate of $\gamma_{1}$ is very imprecisely estimated and fluctuates between -6 and -17 , i.e., a reduction in transportation costs equivalent to a one-block decrease in the distance to the nearest paved street is associated with an increase of per capita consumption of 6-17 Pesos $\$$.

The table also shows that an increase in home valuation is positively associated with an increase in capital, proxied by credit. However, we cannot reject that $\alpha=0$. Indeed, the point estimate is imprecisely estimated. If households were credit constrained, we should expect to find evidence of $\alpha>0$. Unfortunately, we cannot conclude that they are. It is possible that our credit variables are very noisy measures of capital, since using other credit measures as proxies for capital, we still do not find statistically significant results, and some of them flipped the sign of the relationship. This non-statistically significant and unstablesign relationship across capital and home value suggests that we cannot measure capital very well in our context. 


\section{Discussion}

\subsection{External Effects}

Our experimental estimates do not take into account the presence of externalities, in other words, households in the control group may benefit from the pavement provided to the treated group. This is because pavement reduces the distance to the nearest paved not only for houses in the treatment group but also for those in the control group. Indeed, we should expect that this reduction in the distance to the nearest paved street increases home value for houses in the control group. If that is the case, our control group is contaminated, and our previous experimental estimates on the impact of pavement on home value are likely to be downward biased.

We ran a regression of the change in log home value on the change in the distance to the nearest paved street and a constant, where the constant is meant to capture anything that changes between 2006 and 2009 and affects equally the treatment and control groups. Our finding shows that a reduction in distance by one block increased average home value in the control group by $3 \%$, albeit the effect is estimated imprecisely and is not statistically significant $(\mathrm{p}$-value $=0.119)$. Given the experimental estimate on the effect of pavement on home value, $15 \%$, the actual increase in home value due to pavement is around $17 \%$. This additional $2 \%$ comes from the average increase in home value due to distance reduction for the control group, 0.7 blocks, on average. Put it differently, our previous experimental estimate was downward biased by more than $10 \%$.

\subsection{Cost-Benefit Analysis}

To evaluate the desirability of the road pavement experiment, we compare the costs of providing road pavement with its benefits. The costs are measured by looking at the municipality expenditure on road paving. Specifically, in constructing the road projects, the municipality expended 11,304,642 Pesos (2009). More decision making is involved when measuring the 
benefits. In our context, it is reasonable to assume that benefits of the road pavement experiment are captured by the increase experienced in home values. We also need to consider two different scenarios. The first one does not consider external effects, focusing just on the effect of pavement on home values of the treatment group. The second scenario tries to account for external effects, accounting for the average increase on the value of homes located in the control group due to the average decrease in the distance to the nearest paved street.

Table 12 reports the results of our cost benefit analysis (CBA). The top-panel in the table reports the rate of return to the road pavement project absent from external effects. Given the experimental estimated effect on the value of homes located in the treatment group, around $15 \%$ of the average home value in 2006 for the control group, we obtain a rate of return of $2.1 \%$. However, things are dramatically different when we account for external effects. In the bottom-panel, we consider this new scenario. As we already acknowledged, the average increase on the value of homes located in the control group due to the average decrease in the distance to the nearest paved street $(0.72$ blocks $)$ is around $2 \%$. This means that the effect of pavement is $17 \%$, not $15 \%$. The new rate of return is estimated to be around $55 \%$.

Before concluding one important shortcoming of our cost benefit analysis (CBA) must be emphasized: there may have been negative external effects on the set of homes that were already paved. By increasing the supply of homes with road paving in the city, those homes that were already paved could have suffered a reduction in their value as a result of the road pavement experiment. Hence, a note of caution in the interpretation of our CBA is warranted given these potential general equilibrium effects. 


\section{Conclusion}

This study describes results from an experiment in street pavement provision in the slums of the city of Acayucan, Mexico. The study's purpose is to capture impacts and behavioral changes in treated households. This was done through a baseline survey fielded in 2006, and a follow up survey in 2009. Observable characteristics were on average the same between treatment and control groups prior to the intervention. The results suggest that providing pavement significantly increases the value of the properties located in treated streets and thus the value of the collateral households posses. This is reflected in more credit for benefitted households. Benefitted households show an increase in the number of home improvements, number of durable goods, and automobile and truck ownership. Paved roads also generate higher consumption, possibly through the expanded labor income opportunities provided by increased vehicle ownership and more collateral-based credit.

These results provide evidence that lack of urban public infrastructure such as paved roads in a city slum can reduce available credit and consumption among households inhabiting those neighborhoods. The results are encouraging because they suggest that provision of public infrastructure in city slums can reduce poverty in an urban context. 


\section{References}

Angrist, J. D., And J.-S. Pischke (2009): Mostly Harmless Econometrics. An Empiricist's Companion. Princeton University Press.

Antle, J. M. (1983): "Infrastructure and Aggregate Agricultural Productivity: International Evidence," Economic Development and Cultural Change, 31(3), 609-619.

Aschauer, D. A. (1989): "Is Public Expenditure Productive?," Journal of Monetary Economics, 23(2), 177-200.

BanerJee, A. V., and E. Duflo (2007): "The Economic Lives of the Poor," Journal of Economic Perspectives, 21(1), 141-167.

Bean, F. D., A. G. King, and J. S. Passel (1983): "The Number of Illegal Migrants of Mexican Origin in the United States: Sex Ratio-based Estimates for 1980," Demography, 20(1), 99-109.

Bloom, H. (2006): Learning More From Social Experiments. Russell Sage Foundation.

Bloom, H. S. (1984): "Accounting for No-Shows in Experimental Evaluation Designs," Evaluation Review, 8(2), 225-246.

Deaton, A. (1997): The Analysis of Household Surveys. A Microeconometric Approach to Development Policy. John Hopkins University Press.

Dinkelman, T. (2008): "The Effects of Rural Electrification on Employment: New Evidence from South Africa," mimeo, Princeton University.

Duflo, E., And R. Pande (2007): "Dams," Quarterly Journal of Economics, 122(2), 601-646.

Esfahani, H. S., And M. T. Ramirez (2003): "Institutions, Infrastructure, and Economic Growth," Journal of Development Economics, 70(2), 443-477. 
Fan, S., And C. Chan-Kang (2005): "Road Development, Economic Growth, and Poverty Reduction in China," IFPRI Research Report, 138.

Frölich, M., And M. Blaise (2008): "Identification of Treatment Effects on the Treated with One-Sided Non-Compliance," IZA DP No. 3671.

Gonzalez-Navarro, M., and C. Quintana-Domeque (2009): "The Reliability of SelfReported Home Values in a Developing Country Context," Journal of Housing Economics, $18(4)$.

Gramlich, E. M. (1994): "Infrastructure Investment: A Review Essay," Journal of Economic Literature, 32(3), 1176-1196.

Grech, V., P. Vassallo-Agius, and C. Savona-Ventura (2003): "Secular Trends in Sex Ratios at Birth in North America and Europe over the Second Half of the 20th Century," Journal of Epidemiology and Community Health, 57, 612-615.

JACOBy, H. G. (2000): "Access to Markets and the Benefits of Rural Roads," The Economic Journal, 110(465), 713-737.

Jalan, J., And M. Ravallion (2002): "Geographic Poverty Traps? A Micro Model of Consumption Growth in Rural China," Journal of Applied Econometrics, 17(4), 329-346.

Jimenez, E. (1995): "Human and Physical Infrastructure: Public Investment and Pricing Policies in Developing Countries," vol. 3 of Handbook of Development Economics, chap. 43, pp. 2773-2843. Elsevier.

Kling, J. R., J. B. Liebman, and L. F. Katz (2007): "Experimental Analysis of Neighborhood Effects," Econometrica, 75(1), 83-119.

Lokshin, M., And R. Yemtsov (2005): "Has Rural Infrastructure Rehabilitation in Georgia Helped the Poor?," World Bank Economic Review, 19, 311-333. 
Magruder, J. (2009): "High Unemployment Yet Few Small Firms: The Role of Centralized Bargaining in South Africa," UC-Berkeley ARE Mimeo.

Michaels, G. (2008): "The Effect of Trade on the Demand for Skill: Evidence from the Interstate Highway System," Review of Economics and Statistics, 90(4), 683-701.

Shahidur R. Khandker, Zaid Bakht, G. B. K. (2009): "The Poverty Impact of Rural Roads: Evidence from Bangladesh," Economic Development and Cultural Change, 57, $685-722$.

Van De Walle, D. (2002): "Choosing Rural Road Investments to Help Reduce Poverty," World Development, 30(4), 575-589.

Van de Walle, D., and R. Mu (2007): "Fungibility and the Flypaper Effect of Project Aid: Micro-Evidence for Vietnam," Journal of Development Econommics, 84, 667-684.

Welch, B. L. (1947): “The Generalization of 'Student's' Problem when Several Different Population Variances are Involved," Biometrika, 34(1/2), 28-35.

World Bank (1994): "World Development Report 1994 : Infrastructure for Development," Washington D.C. World Bank. 


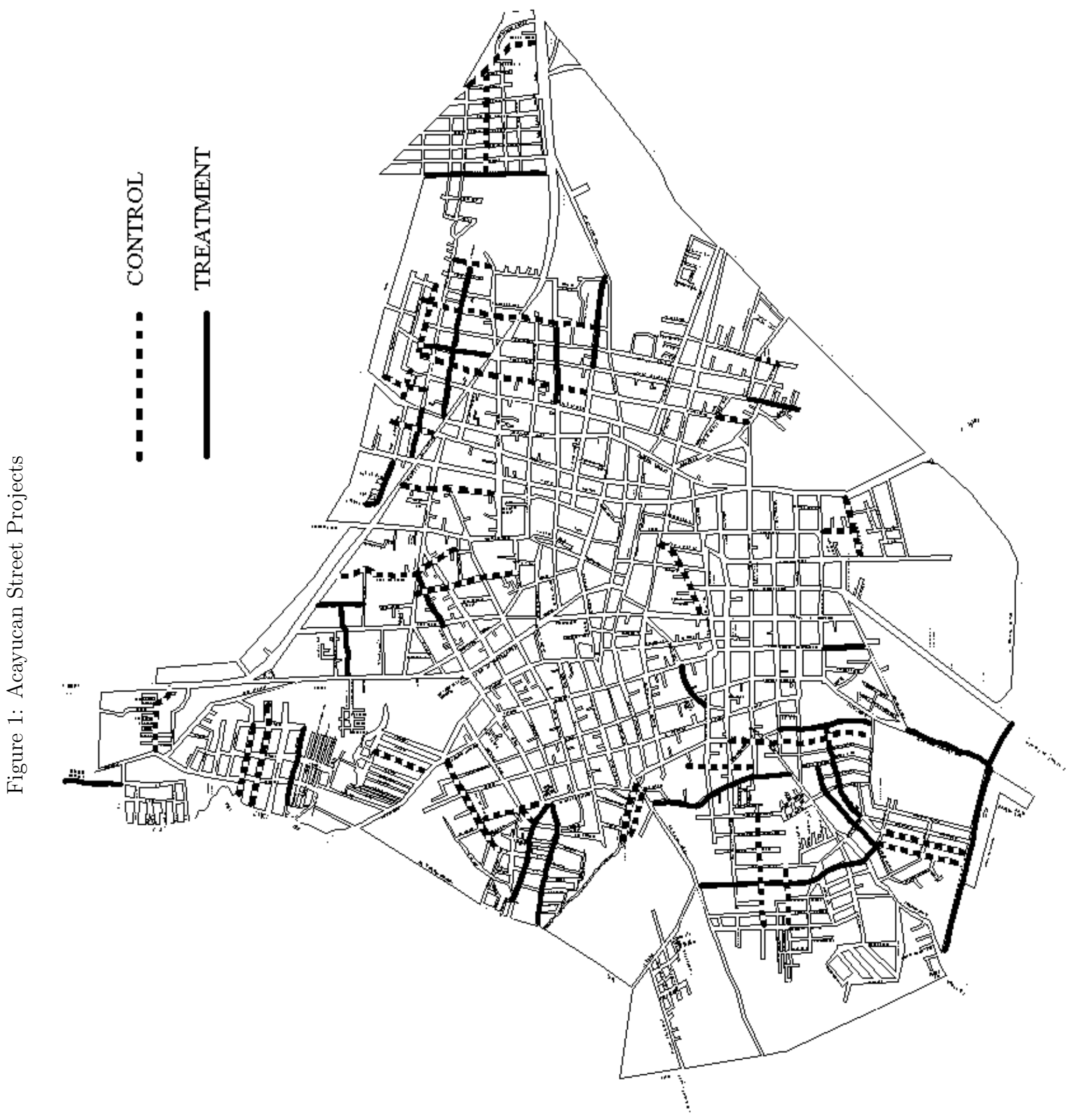




\section{Tables}

Table 1: Comparison to City

\begin{tabular}{lccc}
\hline \hline Individual Level Variables & $\begin{array}{c}\text { Acayucan } \\
(2005 \text { Census })\end{array}$ & $\begin{array}{c}\text { Experiment Streets } \\
\text { (ASLS 2006) }\end{array}$ & $\begin{array}{c}\text { Experiment Streets } \\
\text { (ASLS 2006, Weighted) }\end{array}$ \\
\hline Population & 49,945 & 4,973 & 8,905 \\
Males/Females & $89 \%$ & $89 \%$ & $89 \%$ \\
Share Aged 0-5 & $11 \%$ & $11 \%$ & $11 \%$ \\
Share Aged 65+ & $6 \%$ & $5 \%$ & $5 \%$ \\
15+ Illiterate & $9 \%$ & $11 \%$ & $11 \%$ \\
15+ Incomplete Jr. High School & $16 \%$ & $51 \%$ & $51 \%$ \\
6-14 Not Enrolled in School & $4 \%$ & $4 \%$ & $4 \%$ \\
12-14 Not Enrolled in School & $6 \%$ & $7 \%$ & $7 \%$ \\
15-24 Enrolled in School & $48 \%$ & $48 \%$ & $48 \%$ \\
& & & \\
Household Level Variables & & & 2,220 \\
Families & 12,874 & 1,239 & 2,155 \\
Dwellings & 12,693 & 1,201 & $27 \%$ \\
1 Room Dwelling & $22 \%$ & $27 \%$ & $36 \%$ \\
2 Room Dwelling & $17 \%$ & $36 \%$ & $37 \%$ \\
3+ Room Dwelling & $60 \%$ & $37 \%$ & $21 \%$ \\
No Tap Water in Lot & $16 \%$ & $22 \%$ & $98 \%$ \\
Electricity & $98 \%$ & $98 \%$ & $80 \%$ \\
Fridge & $81 \%$ & $80 \%$ & $52 \%$ \\
Washing Machine & $55 \%$ & $51 \%$ & $11 \%$ \\
Computer & $14 \%$ & $10 \%$ & \\
\hline \hline
\end{tabular}

First column data from locality census Iter 2005 (INEGI). Second and third column data from baseline Acayucan Standards of Living Survey 2006. Weights are the street-project inverse of sampling probability. 
Table 2: Treatment Road Pavement Projects Finish Date

\begin{tabular}{lc}
\hline \hline Project Name & $\begin{array}{c}\text { Road Pavement } \\
\text { Finish Date }\end{array}$ \\
\hline Heroes de Nacozari & Aug. 2007 \\
Belisario Dominguez & Nov. 2007 \\
Calabaza & Dec. 2007 \\
Altamirano & Dec. 2007 \\
Felipe Angeles & Dec. 2007 \\
Salvador Allende & Dec. 2007 \\
Ramon Corona & Dec. 2007 \\
Porvenir & May 2008 \\
Guanajuato & May 2008 \\
Alacio Perez & May 2008 \\
Antonio Plaza-lado izq. & Oct. 2008 \\
Las Arboledas & Dec. 2008 \\
Lombardo Toledano & Feb. 2009 \\
Antonio Plaza & Feb. 2009 \\
David Davila y Bugambilias & Feb. 2009 \\
Lopez Mateos & Feb. 2009 \\
Prol. Murillo Vidal & Feb. 2009 \\
Simon Bolivar & In process \\
Flores Magon & In process \\
Cartas Leandro Valle & In process \\
Gutierrez Zamora & In process \\
Del Arroyo y del Pantano & No progress \\
Ignacio Zaragoza & No progress \\
Prol. Atenogenes Perez y Soto & No progress \\
Juan de Dios Pesa-lado izq. & No progress \\
Veracruz & No progress \\
Cuahutemoc y Calle 6 & No progress \\
Prol. Venustiano Carranza & No progress \\
\hline \hline
\end{tabular}


Table 3: Baseline Descriptive Statistics (2006)

\begin{tabular}{|c|c|c|c|c|c|c|}
\hline Variable & Obs. & Mean & Median & SD & Min & $\operatorname{Max}$ \\
\hline \multicolumn{7}{|l|}{ Demographic Indicators } \\
\hline Household members & 1,231 & 4.01 & 4 & 1.80 & 1 & 16 \\
\hline Female & 4,943 & 0.53 & 1 & 0.50 & 0 & 1 \\
\hline Age & 4,939 & 28.0 & 24 & 19.6 & 0 & 96 \\
\hline Literate & 4,401 & 0.88 & 1 & 0.33 & 0 & 1 \\
\hline Indigenous & 4,401 & 0.03 & 0 & 0.15 & 0 & 1 \\
\hline Has Ever attended school (age >15) & 3,332 & 0.88 & 1 & 0.32 & 0 & 1 \\
\hline Years of schooling $($ age $\geq 15)$ & 3,289 & 7.52 & 8 & 4.7 & 0 & 20 \\
\hline \multicolumn{7}{|l|}{ Housing Quality } \\
\hline Home owner & 1,230 & 0.83 & 1 & 0.36 & 0 & 1 \\
\hline Property title & 1,025 & 0.71 & 1 & 0.45 & 0 & 1 \\
\hline House value estimate & 730 & 194,845 & 100,000 & 281,241 & 3,000 & 300,000 \\
\hline Cement floor & 1,231 & 0.93 & 1 & 0.26 & 0 & 1 \\
\hline Cement roofing & 1,231 & 0.37 & 0 & 0.48 & 0 & 1 \\
\hline Cement walls & 1,229 & 0.92 & 1 & 0.27 & 0 & 1 \\
\hline Rooms & 1,231 & 2.30 & 2 & 1.18 & 1 & 8 \\
\hline Bathroom inside house & 1,231 & 0.59 & 1 & 0.49 & 0 & 1 \\
\hline Wood Fuel & 1,221 & 0.25 & 0 & 0.44 & 0 & 1 \\
\hline \multicolumn{7}{|l|}{ Labor } \\
\hline Worked last week & 4,099 & 0.51 & 1 & 0.50 & 0 & 1 \\
\hline Days worked last week & 2,018 & 5.54 & 6 & 1.55 & 1 & 7 \\
\hline Hours per day & 2,031 & 8.10 & 8 & 3.18 & 0 & 16 \\
\hline Monthly labor income & 1,890 & 2,752 & 2,000 & 3,071 & 0 & 54,500 \\
\hline \multicolumn{7}{|l|}{ Consumption } \\
\hline Household expenditure & 1,203 & 3,268 & 2,800 & 2,218 & 0 & 21,800 \\
\hline Per capita expenditure & 1,203 & 931 & 750 & 738 & 0 & 8,000 \\
\hline Automobile & 1,231 & 0.12 & 0 & 0.32 & 0 & 1 \\
\hline Pick-up truck & 1,231 & 0.08 & 0 & 0.27 & 0 & 1 \\
\hline Sum of durables & 1,231 & 2.07 & 2 & 1.50 & 0 & 7 \\
\hline Refrigerator & 1,231 & 0.79 & 1 & 0.40 & 0 & 1 \\
\hline Washing machine & 1,231 & 0.51 & 1 & 0.50 & 0 & 1 \\
\hline Computer & 1,231 & 0.10 & 0 & 0.30 & 0 & 1 \\
\hline Air conditioning & 1,231 & 0.06 & 0 & 0.24 & 0 & 1 \\
\hline Microwave oven & 1,231 & 0.20 & 0 & 0.40 & 0 & 1 \\
\hline Video player & 1,231 & 0.38 & 0 & 0.48 & 0 & 1 \\
\hline Motorcycle & 1,231 & 0.02 & 0 & 0.15 & 0 & 1 \\
\hline Government program $(=1)$ & 1,231 & 0.07 & 0 & 0.25 & 0 & 1 \\
\hline
\end{tabular}


Table 3: Baseline Descriptive Statistics (2006)

\begin{tabular}{|c|c|c|c|c|c|c|}
\hline Variable & Obs. & Mean & Median & SD & Min & Max \\
\hline \multicolumn{7}{|l|}{ Public services } \\
\hline Distance to nearest paved street & 1,231 & 1.40 & 1 & 1.31 & 0 & 9 \\
\hline Water in lot & 1,229 & 0.78 & 1 & 0.42 & 0 & 1 \\
\hline Sewerage & 1,227 & 0.87 & 1 & 0.34 & 0 & 1 \\
\hline Electricity & 1,230 & 0.98 & 1 & 0.15 & 0 & 1 \\
\hline Garbage collection & 1,230 & 0.58 & 1 & 0.49 & 0 & 1 \\
\hline Burn Garbage & 1,230 & 0.15 & 0 & 0.37 & 0 & 1 \\
\hline Flooding (12 months) & 1,211 & 0.22 & 0 & 0.42 & 0 & 1 \\
\hline Burglary (12 months) & 1,224 & 0.11 & 0 & 0.30 & 0 & 1 \\
\hline $\begin{array}{l}\text { Feel safe walking in } \\
\text { your street at night }\end{array}$ & 1,231 & 0.62 & 1 & 0.52 & 0 & 1 \\
\hline \multicolumn{7}{|l|}{ Credit } \\
\hline Bank Account & 1,221 & 0.17 & 0 & 0.37 & 0 & 1 \\
\hline Credit Card & 1,223 & 0.10 & 0 & 0.30 & 0 & 1 \\
\hline Collateral based private credit & 2,995 & 0.026 & 0 & 0.16 & 0 & 1 \\
\hline Uncollateralized private credit & 2,995 & 0.040 & 0 & 0.20 & 0 & 1 \\
\hline Family or friends credit & 2,995 & 0.007 & 0 & 0.08 & 0 & 1 \\
\hline \multicolumn{7}{|l|}{ Schooling (Ages 5-17) } \\
\hline Literate & 1,405 & 0.87 & 1 & 0.33 & 0 & 1 \\
\hline Enrolled in School & 1,368 & 0.91 & 1 & 0.27 & 0 & 1 \\
\hline Absences Last Month $(>0)$ & 1,243 & 0.21 & 0 & 0.40 & 0 & 1 \\
\hline \multicolumn{7}{|l|}{ Expectations, Investment } \\
\hline Plans to out migrate for work & 1,160 & 0.45 & 0 & 0.55 & 0 & 1 \\
\hline Home improvements ( 6 months) & 1,231 & 0.45 & 0 & 1.08 & 0 & 10 \\
\hline New business (12 months) & 1,231 & 0.05 & 0 & 0.21 & 0 & 1 \\
\hline New business at home & 61 & 0.64 & 1 & 0.47 & 0 & 1 \\
\hline Satisfaction living in city & 1,229 & 3.00 & 3 & 0.70 & 1 & 4 \\
\hline \multicolumn{7}{|l|}{ Business Units } \\
\hline Number of employees & 225 & 1.66 & 1 & 1.22 & 1 & 10 \\
\hline Sales & 225 & 3,370 & 2,000 & 4,260 & 56 & 30,000 \\
\hline Expenditures & 225 & 2,110 & 1,050 & 3,252 & 0 & 27,100 \\
\hline Profits & 225 & 1,260 & 800 & 1,628 & $-1,700$ & 7,600 \\
\hline
\end{tabular}

Mean calculation takes survey weights into account, except in business units, which is a census.

Literate is defined as being able to read and write a note in Spanish, and is asked for people aged 5 and older. Indigenous is defined as speaking an indigenous language, reported for individuals aged 5 and older. Has Ever Attended School and Years of Education are for people aged 15 and older. Property title is not asked for renters. House value estimate in Mexican pesos. Rooms is the number of rooms in the house excluding kitchen, unless it is also used for sleeping. Labor questions are asked for people aged 8 and older. Labor statistics are calculated for the set of people who worked the previous week, except for Worked last week. Hours Per Day is coded as 0 when the person worked an average of less than 1 hour per day, and is top coded at 16 hours. Weekly hours worked is a multiplication of hours per day and days worked last week for each individual that works. PCE is per capita monthly expenditure in Mexican pesos at the household level. Sum of durables is a sum of indicators for: Refrigerator, washing machine, computer, video player, air conditioning, microwave oven, and motorcycle in the household. Government welfare programs include: Liconsa, Progresa-Oportunidades, DIF, etc. Distance to nearest paved street in terms of city blocks, each of around 200 meters. Burn garbage means the household commonly disposes of garbage by burning it. Credit Card and Bank Account are coded as 1 if anyone in the household has them. Other credit questions are asked for all adults 18 and older. Informal private credit sources are: Money lenders, merchants, and local pawn shops. Collateral based credit sources are private bank loans and mortgages. Uncollateralized credit sources are credit cards, furniture and appliance stores, automobile loans, and casas de crédito popular. Home improvements is a sum of indicators of improvements in: flooring, walls, roofing, sewerage connection, plumbing, toilets, electrical, room construction, remodeling, air conditioning installation, security measures, and improvements to house front. 
Table 4: Pre Intervention Balance in Means (Stayers)

\begin{tabular}{|c|c|c|c|c|c|c|c|c|c|}
\hline \multirow[b]{2}{*}{ Variable } & \multicolumn{2}{|c|}{ Group (1) } & \multirow[b]{2}{*}{ Diff. } & \multicolumn{2}{|c|}{ Group (2) } & \multirow[b]{2}{*}{ Diff. } & \multicolumn{2}{|c|}{ Group (3) } & \multirow[b]{2}{*}{ Diff. } \\
\hline & ITT & Control & & Treated & Untreated & & $\begin{array}{c}\text { ITT \& } \\
\text { Treated }\end{array}$ & $\begin{array}{c}\text { ITT \& } \\
\text { Untreated }\end{array}$ & \\
\hline \multicolumn{10}{|c|}{ Demographic Indicators } \\
\hline \multirow[t]{3}{*}{ Household members } & 4.09 & 4.13 & -0.05 & 4.02 & 4.15 & -0.12 & 4.02 & 4.19 & -0.16 \\
\hline & $(0.095)$ & $(0.088)$ & $(0.128)$ & $(0.107)$ & $(0.078)$ & $(0.13)$ & $(0.107)$ & $(0.17)$ & $(0.20)$ \\
\hline & 487 & 413 & 900 & 300 & 600 & 900 & 300 & 187 & 487 \\
\hline \multirow{3}{*}{ Female $(=1)$} & 0.52 & 0.54 & -0.019 & 0.52 & 0.53 & -0.015 & 0.52 & 0.52 & -0.0004 \\
\hline & $(0.007)$ & $(0.011)$ & $(0.013)$ & $(0.009)$ & $(0.009)$ & $(0.013)$ & $(0.009)$ & $(0.011)$ & $(0.014)$ \\
\hline & 1,997 & 1,716 & 3,713 & 1,212 & 2,501 & 3,713 & 1,212 & 785 & 1,997 \\
\hline Adult literate & 0.88 & 0.86 & 0.018 & 0.88 & 0.87 & 0.013 & 0.88 & 0.88 & -0.001 \\
\hline \multirow{2}{*}{$(=1)$} & $(0.012)$ & $(0.007)$ & $(0.014)$ & $(0.018)$ & $(0.007)$ & $(0.019)$ & $(0.018)$ & $(0.014)$ & $(0.022)$ \\
\hline & 1,783 & 1,567 & 3,350 & 1,086 & 2,264 & 3,350 & 1,086 & 697 & 1,783 \\
\hline \multirow{3}{*}{ Adult schooling $(=1)$} & 7.35 & 7.12 & 0.23 & 7.63 & 7.07 & 0.55 & 7.63 & 6.93 & 0.69 \\
\hline & $(0.36)$ & $(0.28)$ & $(0.45)$ & $(0.54)$ & $(0.235)$ & $(0.57)$ & $(0.54)$ & $(0.39)$ & $(0.65)$ \\
\hline & 1,194 & 1,080 & 2,274 & 722 & 1,552 & 2,274 & 722 & 472 & 1,194 \\
\hline \multirow[t]{3}{*}{ Adult age } & 39.88 & 40.77 & -0.89 & 40.31 & 40.42 & -0.11 & 40.31 & 39.22 & 1.09 \\
\hline & $(0.55)$ & $(0.40)$ & $(0.67)$ & $(0.74)$ & $(0.38)$ & $(0.83)$ & $(0.74)$ & $(0.82)$ & $(1.12)$ \\
\hline & 1,251 & 1,107 & 2,358 & 754 & 1,604 & 2,358 & 754 & 497 & 1,251 \\
\hline \multicolumn{10}{|l|}{ Home Characteristics } \\
\hline \multirow{3}{*}{ Homeowner $(=1)$} & 0.93 & 0.94 & -0.011 & 0.93 & 0.94 & -0.006 & 0.93 & 0.93 & 0.004 \\
\hline & $(0.018)$ & $(0.012)$ & $(0.022)$ & $(0.018)$ & $(0.012)$ & $(0.022)$ & $(0.018)$ & $(0.04)$ & $(0.042)$ \\
\hline & 487 & 412 & 899 & 300 & 599 & 899 & 300 & 187 & 487 \\
\hline \multirow{3}{*}{$\begin{array}{l}\text { Log owner estimate } \\
\text { of house price }\end{array}$} & 11.71 & 11.80 & -0.09 & 11.76 & 11.76 & 0.003 & 11.77 & 11.60 & 0.17 \\
\hline & $(0.11)$ & $(0.09)$ & $(0.14)$ & $(0.14)$ & $(0.08)$ & $(0.16)$ & $(0.14)$ & $(0.16)$ & $(0.21)$ \\
\hline & 301 & 290 & 591 & 198 & 393 & 591 & 198 & 103 & 301 \\
\hline \multirow{3}{*}{$\begin{array}{l}\text { Log professional } \\
\text { appraisal of home } \\
\text { value }\end{array}$} & 11.61 & 11.63 & -0.015 & 11.67 & 11.60 & 0.064 & 11.67 & 11.52 & 0.14 \\
\hline & $(0.07)$ & $(0.06)$ & $(0.091)$ & $(0.10)$ & $(0.05)$ & $(0.11)$ & $(0.10)$ & $(0.10)$ & $(0.13)$ \\
\hline & 223 & 195 & 418 & 136 & 282 & 418 & 136 & 87 & 223 \\
\hline Number of rooms & 2.34 & 2.37 & -0.03 & 2.40 & 2.34 & 0.064 & 2.40 & 2.23 & 0.17 \\
\hline & $(0.06)$ & $(0.06)$ & $(0.09)$ & $(0.08)$ & $(0.05)$ & $(0.10)$ & $(0.08)$ & $(0.09)$ & $(0.12)$ \\
\hline & 487 & 413 & 900 & 300 & 600 & 900 & 300 & 187 & 487 \\
\hline Cement roof + & 2.15 & 2.20 & -0.046 & 2.22 & 2.16 & 0.057 & 2.22 & 2.04 & 0.17 \\
\hline cement walls + & $(0.07)$ & $(0.05)$ & $(0.087)$ & $(0.088)$ & $(0.048)$ & $(0.098)$ & $(0.088)$ & $(0.108)$ & $(0.14)$ \\
\hline hard floor $[0-3]$ & 485 & 413 & 898 & 300 & 598 & 900 & 300 & 185 & 485 \\
\hline Bathroom inside & 0.54 & 0.58 & -0.04 & 0.57 & 0.56 & 0.014 & 0.57 & 0.48 & 0.085 \\
\hline house $(=1)$ & $(0.04)$ & $(0.04)$ & $(0.05)$ & $(0.04)$ & $(0.03)$ & $(0.05)$ & $(0.04)$ & $(0.08)$ & $(0.093)$ \\
\hline & 487 & 413 & 900 & 300 & 600 & 900 & 300 & 187 & 487 \\
\hline Water connection & 0.41 & 0.47 & -0.05 & 0.43 & 0.44 & -0.011 & 0.43 & 0.38 & 0.06 \\
\hline inside house $(=1)$ & $(0.05)$ & $(0.04)$ & $(0.06)$ & $(0.07)$ & $(0.04)$ & $(0.07)$ & $(0.07)$ & $(0.09)$ & $(0.11)$ \\
\hline & 487 & 412 & 899 & 300 & 599 & 899 & 300 & 187 & 487 \\
\hline Distance to nearest & 1.486 & 1.351 & 0.135 & 1.48 & 1.38 & 0.099 & 1.48 & 1.49 & -0.009 \\
\hline paved road (blocks) & $(0.16)$ & $(0.147)$ & $(0.216)$ & $(0.20)$ & $(0.128)$ & $(0.233)$ & $(0.20)$ & $(0.26)$ & $(0.33)$ \\
\hline & 487 & 413 & 900 & 300 & 600 & 900 & 300 & 187 & 487 \\
\hline Bought materials for & 0.25 & 0.22 & 0.031 & 0.27 & 0.22 & 0.049 & 0.27 & 0.22 & 0.049 \\
\hline home improvement $(=1)$ & $(0.02)$ & $(0.02)$ & $(0.029)$ & $(0.03)$ & $(0.02)$ & $(0.030)$ & $(0.03)$ & $(0.033)$ & $(0.041)$ \\
\hline & 487 & 412 & 899 & 300 & 599 & 899 & 300 & 187 & 487 \\
\hline Number of home & 0.55 & 0.46 & 0.088 & 0.55 & 0.48 & 0.067 & 0.549 & 0.55 & -0.0007 \\
\hline improvements $[0-13]$ & $(0.05)$ & $(0.05)$ & $(0.072)$ & $(0.06)$ & $(0.05)$ & $(0.076)$ & $(0.060)$ & $(0.097)$ & $(0.117)$ \\
\hline (6 months) & 487 & 413 & 900 & 300 & 600 & 900 & 300 & 187 & 487 \\
\hline Tap water & 0.78 & 0.78 & -0.004 & 0.86 & 0.75 & $0.109^{*}$ & 0.86 & 0.64 & $0.21^{*}$ \\
\hline connection in lot $(=1)$ & $(0.05)$ & $(0.05)$ & $(0.067)$ & $(0.05)$ & $(0.04)$ & $(0.063)$ & $(0.05)$ & $(0.10)$ & $(0.11)$ \\
\hline & 487 & 412 & 899 & 300 & 599 & 900 & 300 & 187 & 487 \\
\hline Sewerage $(=1)$ & 0.84 & 0.88 & -0.04 & 0.87 & 0.86 & 0.003 & 0.87 & 0.80 & 0.06 \\
\hline & $(0.04)$ & $(0.03)$ & $(0.048)$ & $(0.04)$ & $(0.03)$ & $(0.045)$ & $(0.04)$ & $(0.07)$ & $(0.08)$ \\
\hline & 487 & 412 & 899 & 300 & 599 & 899 & 300 & 187 & 487 \\
\hline
\end{tabular}


Table 4: Pre Intervention Balance in Means (Stayers)

\begin{tabular}{|c|c|c|c|c|c|c|c|c|c|}
\hline \multirow[b]{2}{*}{ Variable } & \multicolumn{2}{|c|}{ Group (1) } & \multirow[b]{2}{*}{ Diff. } & \multicolumn{2}{|c|}{ 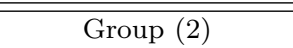 } & \multirow[b]{2}{*}{ Diff. } & \multicolumn{2}{|c|}{ 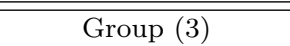 } & \multirow[b]{2}{*}{ Diff. } \\
\hline & ITT & Control & & Treated & Untreated & & $\begin{array}{c}\text { ITT \& } \\
\text { Treated }\end{array}$ & $\begin{array}{c}\text { ITT \& } \\
\text { Untreated }\end{array}$ & \\
\hline \multirow[t]{3}{*}{ Electricity $(=1)$} & 0.98 & 0.98 & 0.0014 & 0.98 & 0.98 & -0.0006 & 0.98 & 0.98 & -0.003 \\
\hline & $(0.005)$ & $(0.014)$ & $(0.015)$ & $(0.007)$ & $(0.011)$ & $(0.013)$ & $(0.007)$ & $(0.008)$ & $(0.011)$ \\
\hline & 486 & 413 & 899 & 299 & 600 & 899 & 299 & 187 & 486 \\
\hline \multirow{3}{*}{ Property title $(=1)$} & 0.71 & 0.75 & -0.043 & 0.71 & 0.74 & -0.030 & 0.71 & 0.70 & 0.006 \\
\hline & $(0.031)$ & $(0.03)$ & $(0.043)$ & $(0.04)$ & $(0.025)$ & $(0.04)$ & $(0.04)$ & $(0.05)$ & $(0.06)$ \\
\hline & 452 & 388 & 840 & 279 & 561 & 840 & 279 & 173 & 452 \\
\hline \multirow{3}{*}{$\begin{array}{l}\text { Garbage collection } \\
(=1)\end{array}$} & 0.52 & 0.59 & -0.068 & 0.58 & 0.55 & 0.030 & 0.58 & 0.42 & 0.16 \\
\hline & $(0.05)$ & $(0.06)$ & $(0.080)$ & $(0.072)$ & $(0.05)$ & $(0.086)$ & $(0.07)$ & $(0.07)$ & $(0.10)$ \\
\hline & 487 & 413 & 899 & 300 & 600 & 900 & 300 & 187 & 487 \\
\hline \multirow{3}{*}{ service $(=1)$} & 0.955 & 0.914 & 0.040 & 0.989 & 0.912 & $0.074^{* * *}$ & 0.989 & 0.903 & $0.08^{* *}$ \\
\hline & $(0.017)$ & $(0.026)$ & $(0.031)$ & $(0.006)$ & $(0.022)$ & $(0.023)$ & $(0.006)$ & (0.039) & $(0.039)$ \\
\hline & 487 & 412 & 899 & 300 & 599 & 899 & 300 & 187 & 487 \\
\hline & 0.37 & 0.48 & -0.10 & 0.40 & 0.45 & -0.048 & 0.40 & 0.34 & 0.05 \\
\hline \multirow{2}{*}{ street $[1-5]$} & $(0.06)$ & $(0.07)$ & $(0.09)$ & $(0.07)$ & $(0.06)$ & (0.087) & $(0.07)$ & $(0.10)$ & $(0.12)$ \\
\hline & 487 & 413 & 900 & 300 & 600 & 900 & 300 & 187 & 487 \\
\hline & 29.54 & 30.47 & -0.92 & 23.10 & 32.63 & -9.53 & 23.10 & 39.83 & -16.73 \\
\hline \multirow{2}{*}{ city center } & $(5.56)$ & $(4.89)$ & $(7.33)$ & $(3.53)$ & $(4.74)$ & $(5.83)$ & (3.53) & (12.56) & $(12.75)$ \\
\hline & 486 & 411 & 897 & 299 & 598 & 897 & 299 & 187 & 486 \\
\hline \multicolumn{10}{|l|}{ Credit } \\
\hline \multirow{3}{*}{$\begin{array}{l}\text { Collateral-based } \\
\text { credit }(=1)\end{array}$} & 0.024 & 0.024 & 0.0006 & 0.025 & 0.023 & 0.002 & 0.025 & 0.023 & 0.002 \\
\hline & $(0.004)$ & $(0.006)$ & $(0.007)$ & $(0.007)$ & $(0.004)$ & $(0.008)$ & $(0.007)$ & $(0.006)$ & $(0.009)$ \\
\hline & 1,215 & 1,089 & 2,304 & 734 & 1,570 & 2,304 & 734 & 481 & 1,215 \\
\hline & 0.044 & 0.032 & 0.012 & 0.046 & 0.034 & 0.012 & 0.046 & 0.041 & 0.005 \\
\hline \multirow{2}{*}{ based credit $(=1)$} & $(0.007)$ & $(0.005)$ & $(0.009)$ & $(0.009)$ & $(0.005)$ & $(0.010)$ & $(0.009)$ & $(0.010)$ & $(0.014)$ \\
\hline & 1,215 & 1,089 & 2,304 & 734 & 1,570 & 2,304 & 734 & 481 & 1,215 \\
\hline \multirow{3}{*}{$\begin{array}{l}\text { Collateral-based } \\
\text { credit amount }\end{array}$} & 535 & 361 & 173 & 543 & 397 & 146 & 544 & 522 & 21 \\
\hline & $(200)$ & $(127)$ & $(234)$ & $(283)$ & $(117)$ & $(301)$ & $(283)$ & $(279)$ & $(393)$ \\
\hline & 1,215 & 1,090 & 2,305 & 734 & 1,571 & 2,305 & 734 & 481 & 1,215 \\
\hline Non-collateral & 420 & 240 & 179 & 479 & 260 & 218 & 478 & 329 & 149 \\
\hline based credit amount & $(110)$ & $(76)$ & $(132)$ & $(163)$ & $(64)$ & $(171)$ & $(163)$ & (119) & $(197)$ \\
\hline & 1,215 & 1,090 & 2,305 & 734 & 1,571 & 2,305 & 734 & 481 & 1,215 \\
\hline Credit card $(=1)$ & 0.09 & 0.09 & 0.008 & 0.12 & 0.08 & 0.041 & 0.12 & 0.05 & $0.066^{*}$ \\
\hline & $(0.02)$ & $(0.01)$ & $(0.024)$ & $(0.03)$ & $(0.009)$ & $(0.035)$ & $(0.034)$ & $(0.015)$ & $(0.04)$ \\
\hline & 484 & 410 & 894 & 298 & 596 & 894 & 298 & 186 & 568 \\
\hline Bank account $(=1)$ & 0.146 & 0.163 & -0.017 & 0.18 & 0.15 & 0.03 & 0.18 & 0.094 & $0.083^{* *}$ \\
\hline & $(0.026)$ & $(0.018)$ & $(0.032)$ & $(0.035)$ & $(0.015)$ & $(0.037)$ & $(0.035)$ & $(0.025)$ & $(0.039)$ \\
\hline & 483 & 410 & 893 & 298 & 595 & 893 & 298 & 185 & 568 \\
\hline Credit from family & 0.004 & 0.005 & -0.0002 & 0.005 & 0.005 & 0.0004 & 0.005 & 0.004 & 0.001 \\
\hline and friends $(=1)$ & $(0.002)$ & $(0.002)$ & $(0.003)$ & $(0.003)$ & $(0.002)$ & $(0.003)$ & $(0.003)$ & $(0.004)$ & $(0.005)$ \\
\hline & 1,215 & 1,089 & 2,304 & 734 & 1,570 & 2,304 & 734 & 481 & 1,215 \\
\hline Informal private & 0.003 & 0.006 & -0.003 & 0.005 & 0.005 & 0.0006 & 0.005 & 0.00 & 0.005 \\
\hline credit $(=1)$ & $(0.001)$ & $(0.002)$ & $(0.003)$ & $(0.002)$ & $(0.002)$ & $(0.003)$ & $(0.002)$ & . & . \\
\hline & 1,215 & 1,089 & 2,304 & 734 & 1,570 & 2,304 & 734 & 481 & 1,215 \\
\hline Labor & & & & & & & & & \\
\hline$\overline{\text { Work }(=1)}$ & 0.603 & 0.596 & 0.006 & 0.611 & 0.595 & 0.017 & 0.611 & 0.589 & 0.022 \\
\hline & $(0.014)$ & $(0.017)$ & $(0.022)$ & $(0.021)$ & $(0.014)$ & $(0.025)$ & $(0.021)$ & $(0.017)$ & $(0.027)$ \\
\hline & 1,127 & 1,001 & 2,128 & 694 & 1,434 & 2,128 & 694 & 433 & 1,127 \\
\hline Unemployed $(=1)$ & 0.048 & 0.072 & -0.023 & 0.052 & 0.065 & -0.013 & 0.052 & 0.041 & 0.011 \\
\hline & $(0.010)$ & $(0.016)$ & $(0.019)$ & $(0.014)$ & $(0.013)$ & $(0.019)$ & $(0.014)$ & $(0.016)$ & $(0.022)$ \\
\hline & 614 & 548 & 1,162 & 383 & 779 & 1,162 & 383 & 231 & 614 \\
\hline Daily hours & 8.39 & 8.19 & 0.201 & 8.297 & 8.262 & 0.035 & 8.297 & 8.534 & -0.236 \\
\hline worked & $(0.174)$ & $(0.147)$ & $(0.226)$ & $(0.243)$ & $(0.126)$ & $(0.267)$ & $(0.243)$ & $(0.215)$ & $(0.316)$ \\
\hline & 523 & 452 & 975 & 323 & 652 & 975 & 323 & 200 & 523 \\
\hline
\end{tabular}


Table 4: Pre Intervention Balance in Means (Stayers)

\begin{tabular}{|c|c|c|c|c|c|c|c|c|c|}
\hline \multirow[b]{2}{*}{ Variable } & \multicolumn{2}{|c|}{ Group (1) } & \multirow[b]{2}{*}{ Diff. } & \multicolumn{2}{|c|}{ 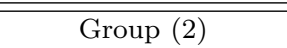 } & \multirow[b]{2}{*}{ Diff. } & \multicolumn{2}{|c|}{$\overline{~ G r o u p ~(3) ~}$} & \multirow[b]{2}{*}{ Diff. } \\
\hline & ITT & Control & & Treated & Untreated & & $\begin{array}{l}\text { ITT \& } \\
\text { Treated }\end{array}$ & $\begin{array}{c}\text { ITT \& } \\
\text { Untreated }\end{array}$ & \\
\hline \multirow{3}{*}{$\begin{array}{l}\text { Monthly log } \\
\text { labor income }\end{array}$} & 7.959 & 7.781 & $0.178^{*}$ & 8.010 & 7.803 & 0.207 & 8.010 & 7.882 & 0.127 \\
\hline & $(0.083)$ & $(0.049)$ & $(0.096)$ & $(0.125)$ & $(0.043)$ & $(0.128)$ & $(0.125)$ & $(0.083)$ & $(0.146)$ \\
\hline & 420 & 390 & 810 & 254 & 556 & 810 & 254 & 166 & 420 \\
\hline Head motor & 0.624 & 0.549 & 0.076 & 0.660 & 0.550 & 0.110 & 0.660 & 0.554 & 0.106 \\
\hline transport to work & $(0.045)$ & $(0.060)$ & $(0.074)$ & $(0.054)$ & $(0.048)$ & $(0.072)$ & $(0.054)$ & $(0.079)$ & $(0.094)$ \\
\hline$(=1)$ & 181 & 111 & 292 & 120 & 172 & 292 & 120 & 61 & 181 \\
\hline Plans out migration & 0.42 & 0.42 & -0.002 & 0.43 & 0.42 & 0.012 & 0.43 & 0.401 & 0.027 \\
\hline \multirow[t]{2}{*}{ for work $(=1)$} & $(0.03)$ & $(0.02)$ & $(0.036)$ & $(0.044)$ & $(0.02)$ & $(0.046)$ & $(0.044)$ & $(0.025)$ & $(0.050)$ \\
\hline & 456 & 286 & 842 & 278 & 564 & 842 & 278 & 178 & 456 \\
\hline Business opening & 0.053 & 0.036 & 0.017 & 0.058 & 0.039 & 0.019 & 0.058 & 0.047 & 0.011 \\
\hline \multirow[t]{2}{*}{ last year $(=1)$} & $(0.012)$ & $(0.009)$ & $(0.015)$ & $(0.018)$ & $(0.007)$ & $(0.019)$ & $(0.018)$ & $(0.015)$ & $(0.023)$ \\
\hline & 487 & 413 & 900 & 300 & 600 & 900 & 300 & 187 & 487 \\
\hline \multicolumn{10}{|l|}{ Consumption } \\
\hline \multirow[t]{2}{*}{$\begin{array}{l}\text { Log per capita } \\
\text { expenditure }\end{array}$} & $\begin{array}{c}6.75 \\
(0.066)\end{array}$ & $\begin{array}{c}6.67 \\
(0.048)\end{array}$ & $\begin{array}{c}0.080 \\
(0.080)\end{array}$ & $\begin{array}{c}6.77 \\
(0.10)\end{array}$ & $\begin{array}{c}6.67 \\
(0.040)\end{array}$ & $\begin{array}{c}0.099 \\
(0.104)\end{array}$ & $\begin{array}{c}6.77 \\
(0.099)\end{array}$ & $\begin{array}{c}6.70 \\
(0.069)\end{array}$ & $\begin{array}{c}0.071 \\
(0.117)\end{array}$ \\
\hline & 470 & 408 & 878 & 292 & 586 & 878 & 292 & 178 & 470 \\
\hline \multirow{3}{*}{$\begin{array}{l}\text { Sum of durable goods } \\
\text { in household }[0-7]\end{array}$} & 2.10 & 2.06 & 0.042 & 2.24 & 2.02 & 0.218 & 2.24 & 1.88 & 0.35 \\
\hline & $(0.14)$ & $(0.078)$ & $(0.161)$ & $(0.219)$ & $(0.066)$ & $(0.226)$ & $(0.219)$ & $(0.128)$ & $(0.25)$ \\
\hline & 497 & 413 & 900 & 300 & 600 & 900 & 300 & 187 & 487 \\
\hline \multirow{3}{*}{$\begin{array}{l}\text { Sum of car and truck } \\
{[0-2]}\end{array}$} & 0.173 & 0.202 & -0.029 & 0.200 & 0.185 & 0.015 & 0.200 & 0.128 & 0.072 \\
\hline & $(0.039)$ & $(0.028)$ & $(0.048)$ & $(0.062)$ & $(0.022)$ & $(0.065)$ & $(0.062)$ & $(0.021)$ & $(0.066)$ \\
\hline & 487 & 413 & 900 & 300 & 600 & 900 & 300 & 187 & 487 \\
\hline \multirow{3}{*}{$\begin{array}{l}\text { Government welfare } \\
\text { program }(=1)\end{array}$} & 0.071 & 0.084 & -0.013 & 0.075 & 0.079 & -0.004 & 0.075 & 0.064 & 0.010 \\
\hline & $(0.018)$ & $(0.015)$ & $(0.023)$ & $(0.025)$ & $(0.013)$ & $(0.027)$ & $(0.025)$ & $(0.025)$ & $(0.035)$ \\
\hline & 487 & 413 & 900 & 300 & 600 & 900 & 300 & 187 & 487 \\
\hline \multirow{3}{*}{$\begin{array}{l}\text { Satisfaction living } \\
\text { in city }[1-4]\end{array}$} & 2.99 & 3.05 & -0.061 & 2.95 & 3.05 & -0.103 & 2.95 & 3.05 & -0.107 \\
\hline & $(0.045)$ & $(0.05)$ & $(0.067)$ & $(0.060)$ & $(0.04)$ & $(0.072)$ & $(0.060)$ & $(0.068)$ & $(0.090)$ \\
\hline & 485 & 413 & 898 & 300 & 598 & 898 & 300 & 185 & 485 \\
\hline \multicolumn{10}{|l|}{ Public Safety } \\
\hline \multirow{3}{*}{$\begin{array}{l}\text { Burglary in past } \\
12 \text { months }(=1)\end{array}$} & 0.11 & 0.11 & -0.004 & 0.103 & 0.115 & -0.012 & 0.103 & 0.12 & -0.016 \\
\hline & $(0.016)$ & $(0.016)$ & $(0.022)$ & $(0.019)$ & $(0.013)$ & $(0.022)$ & $(0.019)$ & $(0.02)$ & $(0.027)$ \\
\hline & 486 & 412 & 898 & 300 & 598 & 898 & 300 & 186 & 486 \\
\hline & 0.62 & 0.61 & 0.017 & 0.67 & 0.59 & 0.075 & 0.67 & 0.55 & $0.12^{*}$ \\
\hline street at night $(=1)$ & $(0.03)$ & $(0.03)$ & $(0.041)$ & $(0.026)$ & $(0.025)$ & $(0.036)$ & $(0.026)$ & $(0.06)$ & $(0.062)$ \\
\hline & 487 & 413 & 900 & 300 & 600 & 900 & 300 & 187 & 487 \\
\hline Vehicle stolen or & 0.069 & 0.020 & 0.049 & 0.034 & 0.050 & -0.016 & 0.034 & 0.164 & $-0.13^{*}$ \\
\hline vandalized (=1) & $(0.036)$ & $(0.019)$ & $(0.040)$ & $(0.029)$ & $(0.023)$ & $(0.036)$ & $(0.029)$ & $(0.070)$ & $(0.072)$ \\
\hline (12 months) & 65 & 46 & 111 & 47 & 64 & 111 & 47 & 18 & 65 \\
\hline Schooling of Childre & Age 5-1 & & & & & & & & \\
\hline Age children $(=1)$ & 9.10 & 9.46 & -0.36 & 9.20 & 9.33 & -0.136 & 9.20 & 8.94 & 0.26 \\
\hline & $(0.27)$ & $(0.22)$ & $(0.34)$ & $(0.37)$ & $(0.19)$ & $(0.402)$ & $(0.37)$ & $(0.37)$ & $(0.51)$ \\
\hline & 744 & 607 & 1,351 & 457 & 894 & 1,351 & 457 & 287 & 744 \\
\hline Literate $(=1)$ & 0.86 & 0.88 & -0.011 & 0.85 & 0.88 & -0.028 & 0.85 & 0.89 & -0.04 \\
\hline & $(0.02)$ & $(0.01)$ & $(0.023)$ & $(0.03)$ & $(0.01)$ & $(0.030)$ & $(0.03)$ & $(0.02)$ & $(0.03)$ \\
\hline & 568 & 478 & 1,046 & 352 & 694 & 1,046 & 352 & 216 & 568 \\
\hline Enrollment in & 0.94 & 0.93 & 0.008 & 0.94 & 0.94 & -0.0005 & 0.94 & 0.95 & -0.01 \\
\hline school $(=1)$ & $(0.01)$ & $(0.01)$ & $(0.016)$ & $(0.015)$ & $(0.01)$ & $(0.018)$ & $(0.016)$ & $(0.01)$ & $(0.021)$ \\
\hline & 556 & 471 & 1,027 & 344 & 683 & 1,027 & 344 & 212 & 556 \\
\hline Absences $>0$ last & 0.19 & 0.18 & 0.002 & 0.20 & 0.18 & 0.017 & 0.20 & 0.17 & 0.029 \\
\hline month $(=1)$ & $(0.01)$ & $(0.02)$ & $(0.026)$ & $(0.02)$ & $(0.02)$ & $(0.026)$ & $(0.02)$ & $(0.02)$ & $(0.030)$ \\
\hline & 522 & 432 & 954 & 322 & 632 & 954 & 322 & 200 & 522 \\
\hline
\end{tabular}


Table 4: Pre Intervention Balance in Means (Stayers)

\begin{tabular}{|c|c|c|c|c|c|c|c|c|c|}
\hline \multirow[b]{2}{*}{ Variable } & \multicolumn{2}{|c|}{ Group (1) } & \multirow[b]{2}{*}{ Diff. } & \multicolumn{2}{|c|}{ Group (2) } & \multirow[b]{2}{*}{ Diff. } & \multicolumn{2}{|c|}{ Group (3) } & \multirow[b]{2}{*}{ Diff. } \\
\hline & ITT & Control & & Treated & Untreated & & $\begin{array}{l}\text { ITT \& } \\
\text { Treated }\end{array}$ & $\begin{array}{c}\text { ITT \& } \\
\text { Untreated }\end{array}$ & \\
\hline \multicolumn{10}{|l|}{ Health } \\
\hline \multirow[t]{3}{*}{ Sick last month } & 0.48 & 0.46 & $0.017^{* *}$ & 0.50 & 0.45 & 0.048 & 0.50 & 0.43 & $0.67^{*}$ \\
\hline & $(0.02)$ & $(0.02)$ & $(0.029)$ & $(0.025)$ & $(0.017)$ & $(0.030)$ & $(0.025)$ & $(0.03)$ & $(0.036)$ \\
\hline & 1,950 & 1,690 & 3,640 & 1,184 & 2,456 & 3,640 & 1,184 & 766 & 1,950 \\
\hline & 0.137 & 0.16 & -0.023 & 0.148 & 0.152 & -0.003 & 0.148 & 0.119 & 0.028 \\
\hline \multirow{2}{*}{ skin infections } & $(0.014)$ & $(0.02)$ & $(0.021)$ & $(0.016)$ & $(0.013)$ & $(0.021)$ & $(0.016)$ & $(0.026)$ & $(0.031)$ \\
\hline & 1,950 & 1,690 & 3,640 & 1,184 & 2,456 & 3,640 & 1,184 & 766 & 1,950 \\
\hline \multicolumn{10}{|c|}{ Satisfaction with Government } \\
\hline Satisfaction with & 2.29 & 2.31 & -0.02 & 2.25 & 2.32 & -0.067 & 2.25 & 2.35 & -0.097 \\
\hline \multirow[t]{2}{*}{ local government } & $(0.05)$ & $(0.054)$ & $(0.076)$ & $(0.073)$ & $(0.045)$ & $(0.084)$ & $(0.073)$ & $(0.07)$ & $(0.102)$ \\
\hline & 476 & 398 & 874 & 296 & 578 & 874 & 296 & 180 & 476 \\
\hline Satisfaction with & 2.47 & 2.54 & -0.065 & 2.46 & 2.53 & -0.072 & 2.46 & 2.50 & -0.043 \\
\hline \multirow[t]{2}{*}{ State government } & $(0.04)$ & $(0.036)$ & $(0.055)$ & $(0.059)$ & $(0.030)$ & $(0.065)$ & $(0.059)$ & $(0.053)$ & $(0.078)$ \\
\hline & 466 & 393 & 859 & 291 & 568 & 859 & 291 & 175 & 466 \\
\hline Satisfaction with & 2.53 & 2.54 & -0.009 & 2.56 & 2.53 & 0.031 & 2.56 & 2.48 & 0.075 \\
\hline \multirow[t]{2}{*}{ Federal government } & $(0.04)$ & $(0.04)$ & $(0.058)$ & $(0.049)$ & $(0.036)$ & $(0.060)$ & $(0.049)$ & $(0.073)$ & $(0.088)$ \\
\hline & 471 & 399 & 870 & 292 & 578 & 870 & 292 & 179 & 471 \\
\hline & 0.85 & 0.88 & -0.034 & 0.87 & 0.86 & 0.002 & 0.87 & 0.81 & $0.055^{*}$ \\
\hline \multirow[t]{2}{*}{ roads in city } & $(0.016)$ & $(0.02)$ & $(0.026)$ & $(0.019)$ & $(0.017)$ & $(0.025)$ & $(0.019)$ & $(0.024)$ & $(0.029)$ \\
\hline & 487 & 413 & 900 & 300 & 600 & 900 & 300 & 187 & 487 \\
\hline \multicolumn{10}{|c|}{ Business Unit Census } \\
\hline \multirow[t]{3}{*}{ Number of employees } & 1.78 & 1.56 & 0.22 & 1.84 & 1.59 & 0.25 & 1.83 & 1.68 & 0.16 \\
\hline & $(0.13)$ & $(0.10)$ & $(0.16)$ & $(0.20)$ & $(0.08)$ & $(0.22)$ & $(0.19)$ & $(0.14)$ & $(0.25)$ \\
\hline & 102 & 123 & 225 & 64 & 161 & 225 & 64 & 38 & 108 \\
\hline \multirow[t]{3}{*}{ Log sales } & 7.72 & 7.62 & 0.10 & 7.77 & 7.62 & 0.15 & 7.77 & 7.64 & 0.13 \\
\hline & $(0.14)$ & $(0.12)$ & $(0.19)$ & $(0.18)$ & $(0.12)$ & $(0.22)$ & $(0.18)$ & $(0.30)$ & $(0.37)$ \\
\hline & 102 & 123 & 225 & 64 & 161 & 225 & 64 & 38 & 102 \\
\hline \multirow[t]{3}{*}{ Log expenditures } & 7.19 & 7.00 & 0.18 & 7.14 & 7.07 & 0.06 & 7.14 & 7.29 & -0.15 \\
\hline & $(0.17)$ & $(0.15)$ & $(0.23)$ & $(0.25)$ & $(0.13)$ & $(0.28)$ & $(0.25)$ & $(0.22)$ & $(0.34)$ \\
\hline & 98 & 117 & 215 & 63 & 152 & 215 & 63 & 35 & 98 \\
\hline \multirow{3}{*}{ Log profits } & 6.89 & 6.89 & 0.005 & 6.92 & 6.88 & 0.04 & 6.92 & 6.85 & 0.075 \\
\hline & $(0.13)$ & $(0.13)$ & $(0.18)$ & $(0.15)$ & $(0.12)$ & $(0.20)$ & $(0.15)$ & $(0.31)$ & $(0.36)$ \\
\hline & 94 & 107 & 201 & 60 & 141 & 201 & 60 & 34 & 94 \\
\hline
\end{tabular}

Coefficients from OLS regressions using survey weights. Standard errors clustered at the road pavement project level Coefficients from OLS regressions using survey weights. Standard errors clustered at the road pavement project level

Business units regressions use clustered standard errors at the road pavement project level. Business units analysis includes all firms with complete information from 2006 with a $5 \%$ trimming according to profit rank from above and below. Expenditures Sales and Profits in terms of 2009 Mexican pesos.

Literate is defined as being able to read and write a note in Spanish, and is asked for people aged 5 and older.

Adult is defined as being aged 18 and older.

$P C E$ is per capita monthly expenditure in Mexican pesos at the household level.

Estimate of house value in 2006 Mexican Pesos.

Number of Rooms is the number of rooms in the house excluding kitchen, unless it is also used for sleeping.

Informal private credit sources are: Money lenders, merchants, and local pawn shops.

Collateral based credit sources are private bank loans and mortgages. Uncollateralized credit sources are credit cards, furniture and appliance stores automobile loans, and casas de crédito popular.

Credit Card and Bank Account are coded as 1 if anyone in the household has them. Other credit questions are asked for all adults 18 and older.

Durable goods in household is a sum of dummies for having: Refrigerator, washing machine, computer, video player, air conditioning, microwave oven, and motorcycle.

Government welfare programs include: Liconsa, Progresa-Oportunidades, DIF, etc.

Labor questions are asked for people aged 8 and older. Labor statistics are calculated for the set of people who worked the previous week, except for Worked last week. Hours Per Day is coded as 0 when the person worked an average of less than 1 hour per day, and is top coded at 16 hours. Weekly hours worked is a multiplication of hours per day and days worked last week for each individual that works Home improvements is a sum of indicators for improving: flooring, walls, roofing, sewerage connection, plumbing, toilets, electrical, room construction, remodeling, air conditioning, security measures, and house front.

Distance to nearest paved street in terms of city blocks, each of around 200 meters.

Satisfaction with Government on a 4 point scale where: 1 is very unsatisfied, 2 is unsatisfied, 3 is satisfied and 4 is very satisfied. 
Table 5: Non Response and Recontact

\begin{tabular}{|c|c|c|c|}
\hline \multicolumn{3}{|c|}{$\begin{array}{c}2006 \\
\text { Dwellings } \\
\end{array}$} & $\begin{array}{c}2009 \\
\text { Households }\end{array}$ \\
\hline \multirow{12}{*}{$\begin{array}{l}\text { Eligible selected } \\
\text { Completed } \\
\text { Response rate }\end{array}$} & 1,275 & Follow up & 1,231 \\
\hline & 1,193 & Completed at follow up & 900 \\
\hline & $94 \%$ & Household moved & 271 \\
\hline & & Non response & 56 \\
\hline & & Other & 4 \\
\hline & & Recontact rate & $73 \%$ \\
\hline & & $\begin{array}{l}\text { New households } \\
\text { of which: }\end{array}$ & 183 \\
\hline & & Subdivision & 22 \\
\hline & & Substitution & 120 \\
\hline & & New household & 14 \\
\hline & & New construction & 27 \\
\hline & & Completed in 2009 & 1,083 \\
\hline
\end{tabular}

Eligible dwelling category excluded plots without a dwelling, unoccupied dwellings or temporary use dwellings.

2006 non response is in terms of dwellings selected from the frame, and the number of dwellings with completed household survey. 2009 recontact is in terms of households. There were 1,231 households in 1,193 dwellings in 2006, so that in some cases there is more than one household per dwelling.

Completed at follow up is defined as having recontacted at least one member of the household interviewed in 2006.

New households defined as not having been interviewed in 2006.

Subdivisions happen when one of the members in 2006 creates a new household living in the same plot, for example if the son gets married and lives in his parent's house but does not share food expenses.

Substitutions are new households found in 2009 that occupy the dwelling inhabited by an interviewed family in 2006, for example if the house is rented.

New household occurs when the interviewed family is still in the dwelling, but now there is an additional household, for example if a room in the house is now rented out.

New constructions are households interviewed in which the residential structure was not there in 2006 but is there in 2009 . 
Table 6: Outmigration and Immigration

\begin{tabular}{lcc}
\hline \hline Outmigration & \multicolumn{2}{c}{$y=1$ if household outmigrated } \\
& OLS & IV \\
\hline Pavement & -0.010 & 0.013 \\
& $(0.026)$ & $(0.044)$ \\
Constant & $0.24^{* * *}$ & $0.23^{* * *}$ \\
& $(0.018)$ & $(0.022)$ \\
\cline { 2 - 3 } Obs & 1,171 & 1,171 \\
& & \\
\hline \multirow{3}{*}{ Immigration } & $y=1$ if household immigrated \\
& OLS & IV \\
\hline Pavement & -0.012 & -0.012 \\
& $(0.023)$ & $(0.039)$ \\
Constant & $0.17^{* * *}$ & $0.17^{* * *}$ \\
& $(0.01)$ & $(0.02)$ \\
\cline { 2 - 3 } Obs & 1,083 & 1,083 \\
\hline \hline
\end{tabular}

Weighted regressions, standard errors clustered at the road pavement project level.

Dependent variable is a dummy for household having outmigrated (immigrated) by 2009. Probit specification yields same results.

In the top panel the sample is households who were surveyed in 2006. In the lower panel the sample is households interviewed in 2009 . 


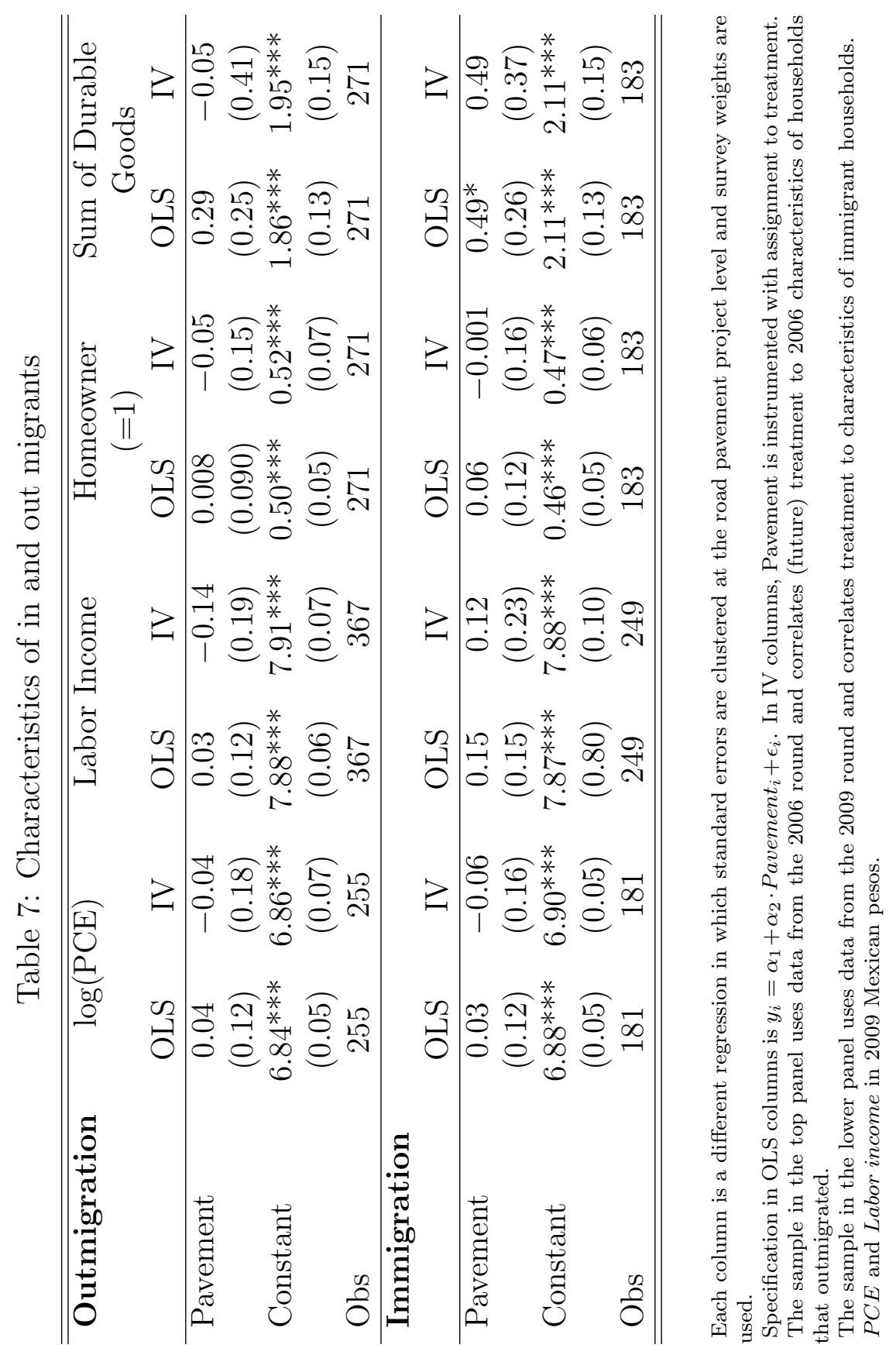


Table 8: Impacts on Stayers

\begin{tabular}{|c|c|c|c|c|c|}
\hline Variable & OLS & OLS+LO & IV & $\mathrm{IV}+\mathrm{LO}$ & Mean Control 2009 \\
\hline \multicolumn{6}{|l|}{ Home Characteristics } \\
\hline \multirow{3}{*}{$\begin{array}{l}\text { Distance to nearest paved street } \\
\text { (in number of street blocks) }\end{array}$} & $-0.623^{* * *}$ & $-0.651^{* * *}$ & $-0.636^{* * *}$ & $-0.709^{* * *}$ & $0.645^{* * *}$ \\
\hline & $(0.068)$ & $(0.076)$ & $(0.153)$ & $(0.124)$ & $(0.069)$ \\
\hline & 893 & 893 & 893 & 893 & 764 \\
\hline \multirow[t]{3}{*}{ Homeowner (vs renter) $(=1)$} & -0.009 & -0.001 & -0.030 & -0.019 & 0.954 \\
\hline & $(0.022)$ & $(0.009)$ & $(0.036)$ & $(0.015)$ & $(0.014)$ \\
\hline & 897 & 897 & 897 & 897 & 411 \\
\hline \multirow[t]{3}{*}{ Log owner estimate of house price } & 0.230 & $0.201^{*}$ & 0.189 & $0.241^{*}$ & 11.99 \\
\hline & $(0.177)$ & $(0.102)$ & $(0.225)$ & $(0.143)$ & $(0.081)$ \\
\hline & 535 & 535 & 535 & 535 & 275 \\
\hline \multirow{3}{*}{$\begin{array}{l}\text { Log professional appraisal } \\
\text { of house price }\end{array}$} & 0.174 & $0.133^{* * *}$ & 0.110 & $0.146^{* * *}$ & 11.57 \\
\hline & $(0.114)$ & $(0.038)$ & $(0.153)$ & $(0.047)$ & $(0.061)$ \\
\hline & 394 & 394 & 394 & 394 & 185 \\
\hline \multirow{3}{*}{$\begin{array}{l}\text { Bought material for home } \\
\text { improvement }(=1) \text { ( } 6 \text { months) }\end{array}$} & $0.053^{* *}$ & $0.047^{*}$ & $0.090^{*}$ & $0.084^{*}$ & 0.146 \\
\hline & $(0.026)$ & $(0.026)$ & $(0.046)$ & $(0.046)$ & $(0.021)$ \\
\hline & 894 & 894 & 894 & 894 & 409 \\
\hline \multirow{3}{*}{$\begin{array}{l}\text { Number of home improvements } \\
{[0-13](6 \text { months })}\end{array}$} & $0.215^{*}$ & $0.207^{*}$ & $0.435 * *$ & $0.419^{* *}$ & 0.400 \\
\hline & $(0.120)$ & $(0.118)$ & $(0.201)$ & $(0.200)$ & $(0.064)$ \\
\hline & 900 & 900 & 900 & 900 & 413 \\
\hline \multirow{3}{*}{$\begin{array}{l}\text { Cement roof }+ \text { cement walls }+ \\
\text { hard floor }[0-3]\end{array}$} & 0.081 & 0.028 & -0.053 & -0.016 & 2.25 \\
\hline & $(0.094)$ & $(0.039)$ & $(0.130)$ & $(0.058)$ & $(0.047)$ \\
\hline & 894 & 894 & 894 & 894 & 411 \\
\hline \multirow[t]{3}{*}{ Number of rooms } & 0.043 & 0.004 & -0.039 & -0.015 & 2.43 \\
\hline & $(0.131)$ & $(0.094)$ & $(0.189)$ & $(0.137)$ & $(0.079)$ \\
\hline & 900 & 900 & 900 & 900 & 413 \\
\hline \multicolumn{6}{|l|}{ Credit } \\
\hline \multirow{3}{*}{ Collateral based credit $(=1)$} & 0.018 & 0.018 & $0.028^{*}$ & $0.028^{*}$ & 0.018 \\
\hline & $(0.011)$ & $(0.011)$ & $(0.014)$ & $(0.014)$ & $(0.004)$ \\
\hline & 1,984 & 1,984 & 1,984 & 1,984 & 937 \\
\hline \multirow{3}{*}{ Non-Collateral based credit $(=1)$} & 0.001 & -0.001 & 0.002 & -0.001 & 0.069 \\
\hline & $(0.011)$ & $(0.012)$ & $(0.019)$ & $(0.019)$ & $(0.009)$ \\
\hline & 1,984 & 1,984 & 1,984 & 1,984 & 937 \\
\hline \multirow[t]{3}{*}{ Collateral based credit amount } & $1,627^{*}$ & $1,613^{* *}$ & $1,759^{* *}$ & $1,740^{* *}$ & 427.1 \\
\hline & $(816)$ & $(799)$ & $(827)$ & $(811)$ & $(92.2)$ \\
\hline & 1,984 & 1,984 & 1,984 & 1,984 & 937 \\
\hline \multirow[t]{3}{*}{ Non-collateral based credit amount } & 233 & 236 & 412 & 416 & 716 \\
\hline & (421) & (424) & (577) & (581) & (178) \\
\hline & 1,984 & 1,984 & 1,984 & 1,984 & 1,134 \\
\hline \multirow[t]{3}{*}{ Credit card $(=1)$} & 0.056 & 0.047 & 0.058 & 0.055 & 0.155 \\
\hline & $(0.037)$ & $(0.036)$ & $(0.053)$ & $(0.052)$ & $(0.021)$ \\
\hline & 890 & 890 & 890 & 890 & 410 \\
\hline \multirow{3}{*}{ Bank account $(=1)$} & $0.059^{*}$ & 0.048 & 0.065 & 0.070 & 0.138 \\
\hline & $(0.035)$ & $(0.032)$ & (0.049) & $(0.044)$ & $(0.020)$ \\
\hline & 891 & 891 & 891 & 891 & 410 \\
\hline
\end{tabular}


Table 8: Impacts on Stayers

\begin{tabular}{|c|c|c|c|c|c|}
\hline Variable & OLS & OLS+LO & IV & IV+LO & Mean Control 2009 \\
\hline \multicolumn{6}{|l|}{ Labor } \\
\hline \multirow[t]{3}{*}{ Work $(=1)$} & -0.021 & -0.029 & -0.027 & -0.031 & 0.627 \\
\hline & $(0.026)$ & $(0.023)$ & $(0.037)$ & $(0.032)$ & $(0.015)$ \\
\hline & 2,128 & 2,128 & 2,128 & 2,128 & 1,001 \\
\hline \multirow[t]{3}{*}{ Unemployed $(=1)$} & 0.004 & 0.006 & -0.009 & -0.004 & 0.076 \\
\hline & $(0.023)$ & $(0.023)$ & $(0.031)$ & $(0.031)$ & $(0.014)$ \\
\hline & 1,162 & 1,162 & 1,162 & 1,162 & 548 \\
\hline \multirow{3}{*}{ Daily work hours } & 0.306 & 0.292 & $0.682^{* *}$ & $0.543^{*}$ & 8.24 \\
\hline & $(0.284)$ & $(0.226)$ & $(0.396)$ & $(0.310)$ & $(0.166)$ \\
\hline & 975 & 975 & 975 & 975 & 452 \\
\hline \multirow{3}{*}{ Log labor income } & $0.244^{* *}$ & $0.143^{* * *}$ & 0.195 & 0.050 & 7.82 \\
\hline & $(0.100)$ & $(0.051)$ & $(0.130)$ & $(0.081)$ & $(0.046)$ \\
\hline & 810 & 810 & 810 & 810 & 390 \\
\hline \multirow{3}{*}{ Plans to migrate for work $(=1)$} & $-0.065^{*}$ & $-0.065^{*}$ & $-0.106^{*}$ & $-0.103^{*}$ & 0.474 \\
\hline & $(0.038)$ & $(0.035)$ & $(0.058)$ & $(0.055)$ & $(0.027)$ \\
\hline & 801 & 801 & 801 & 801 & 370 \\
\hline \multirow{3}{*}{$\begin{array}{l}\text { Head motor transport } \\
\text { to work }(=1)\end{array}$} & $0.220^{* * *}$ & $0.160^{* * *}$ & $0.252^{* * *}$ & $0.292^{* * *}$ & 0.492 \\
\hline & $(0.068)$ & $(0.050)$ & $(0.089)$ & $(0.066)$ & $(0.042)$ \\
\hline & 292 & 292 & 292 & 292 & 111 \\
\hline \multicolumn{6}{|l|}{ Consumption } \\
\hline \multirow[t]{3}{*}{ Log per capita expenditure } & $0.122^{*}$ & $0.0788^{*}$ & $0.158^{*}$ & 0.101 & 6.73 \\
\hline & $(0.066)$ & $(0.038)$ & $(0.093)$ & $(0.063)$ & $(0.027)$ \\
\hline & 822 & 822 & 822 & 822 & 385 \\
\hline \multirow{3}{*}{$\begin{array}{l}\text { Sum of durable goods in } \\
\text { household }[0-7]\end{array}$} & 0.381 & $0.209^{*}$ & 0.337 & $0.261^{*}$ & 2.41 \\
\hline & $(0.266)$ & $(0.114)$ & $(0.299)$ & $(0.153)$ & $(0.079)$ \\
\hline & 900 & 900 & 897 & 897 & 413 \\
\hline \multirow[t]{3}{*}{ Sum of car and truck [0-2] } & $0.127^{*}$ & $0.106^{* * *}$ & 0.096 & $0.113^{* *}$ & 0.202 \\
\hline & $(0.072)$ & $(0.038)$ & $(0.083)$ & $(0.051)$ & $(0.025)$ \\
\hline & 900 & 900 & 900 & 900 & 413 \\
\hline \multirow{3}{*}{ Government welfare program $(=1)$} & -0.001 & -0.001 & -0.004 & -0.004 & 0.033 \\
\hline & $(0.013)$ & $(0.013)$ & $(0.019)$ & $(0.019)$ & $(0.009)$ \\
\hline & 897 & 897 & 897 & 897 & 411 \\
\hline
\end{tabular}


Table 8: Impacts on Stayers

\begin{tabular}{lccccc}
\hline \hline Variable & OLS & OLS+LO & IV & IV+LO & Mean Control 2009 \\
\hline Public safety & & & & & \\
Burglary (=1) & 0.010 & 0.011 & 0.048 & 0.049 & 0.060 \\
$(12$ months) & $(0.020)$ & $(0.020)$ & $(0.034)$ & $(0.033)$ & $(0.012)$ \\
& 893 & 893 & 893 & 893 & 410 \\
Vehicle stolen/vandalized (=1) & -0.009 & -0.011 & 0.001 & 0.007 & 0.094 \\
$(12$ months) & $(0.051)$ & $(0.052)$ & $(0.071)$ & $(0.072)$ & $(0.044)$ \\
& 111 & 111 & 111 & 111 & 46 \\
Health & & & & & \\
Sick last month (=1) & -0.024 & -0.031 & -0.005 & -0.008 & 0.523 \\
& $(0.023)$ & $(0.023)$ & $(0.039)$ & $(0.039)$ & $(0.017)$ \\
Parasites or fungus last year & 3,152 & 3,152 & 3,152 & 3,152 & 1,445 \\
$(=1)$ & -0.004 & -0.003 & 0.003 & 0.010 & 0.167 \\
Schooling & $(0.023)$ & $(0.022)$ & $(0.037)$ & $(0.036)$ & $(0.017)$ \\
School enrollment (=1) & 3,145 & 3,145 & 3,145 & 3,145 & 1,444 \\
& & & & & \\
Absenteeism last month $(=1)$ & -0.003 & 0.002 & 0.019 & 0.022 & 0.939 \\
& $(0.021)$ & $(0.020)$ & $(0.030)$ & $(0.028)$ & $(0.013)$ \\
& 700 & 700 & 700 & 700 & 313 \\
& 0.054 & 0.051 & 0.048 & 0.045 & 0.140 \\
\hline \hline
\end{tabular}

IV uses intent to treat assignment as the instrumental variable for getting road pavement. $L O$ stands for lagged outcome included as regressor. regressions use survey weights and standard errors clustered at the street project level.

Home value estimate, Professional appraisal in 2009 Mexican pesos.

Rooms is the number of rooms in the house excluding kitchen, unless it is also used for sleeping.

Collateral based credit is one for mortgages and bank loans. Non collateral basedcredit is one for store credit (appliances, furniture, etc.), automobile loan, credit card and casa de credito popular.

Labor questions are asked for individuals aged 18-59. Work is one if the person worked last week or has work but is on leave, 0 otherwise (0 includes students, housewives, etc.) Employed distinguishes employed from unemployed (Excluding students, housewives, etc.) Daily hours is top coded at 16 hours.

HHD motor transport to work is one if the head of the household uses a car, bus or taxi to go to work.

Per capita expenditure at the household level in 2009 Mexican pesos, $1 \%$ trimmed from above and below.

Government welfare programs include: Liconsa, Progresa-Oportunidades, DIF, etc.

Sum of durables is a sum of indicators for: Refrigerator, washing machine, computer, video player, air conditioning, microwave oven, and motorcycle in the household.

Sick Last Month $=1$ if Vomit, diarrhea, bronchitis, stomach pain, flu, fever, coughing were present in the past month. Infection/parasite Last Year $=1$ if person presented or was diagnosed skin infection, fungus in feet or hands, or intestinal parasites in the past year.

Schooling outcomes are for children aged 5-17. 


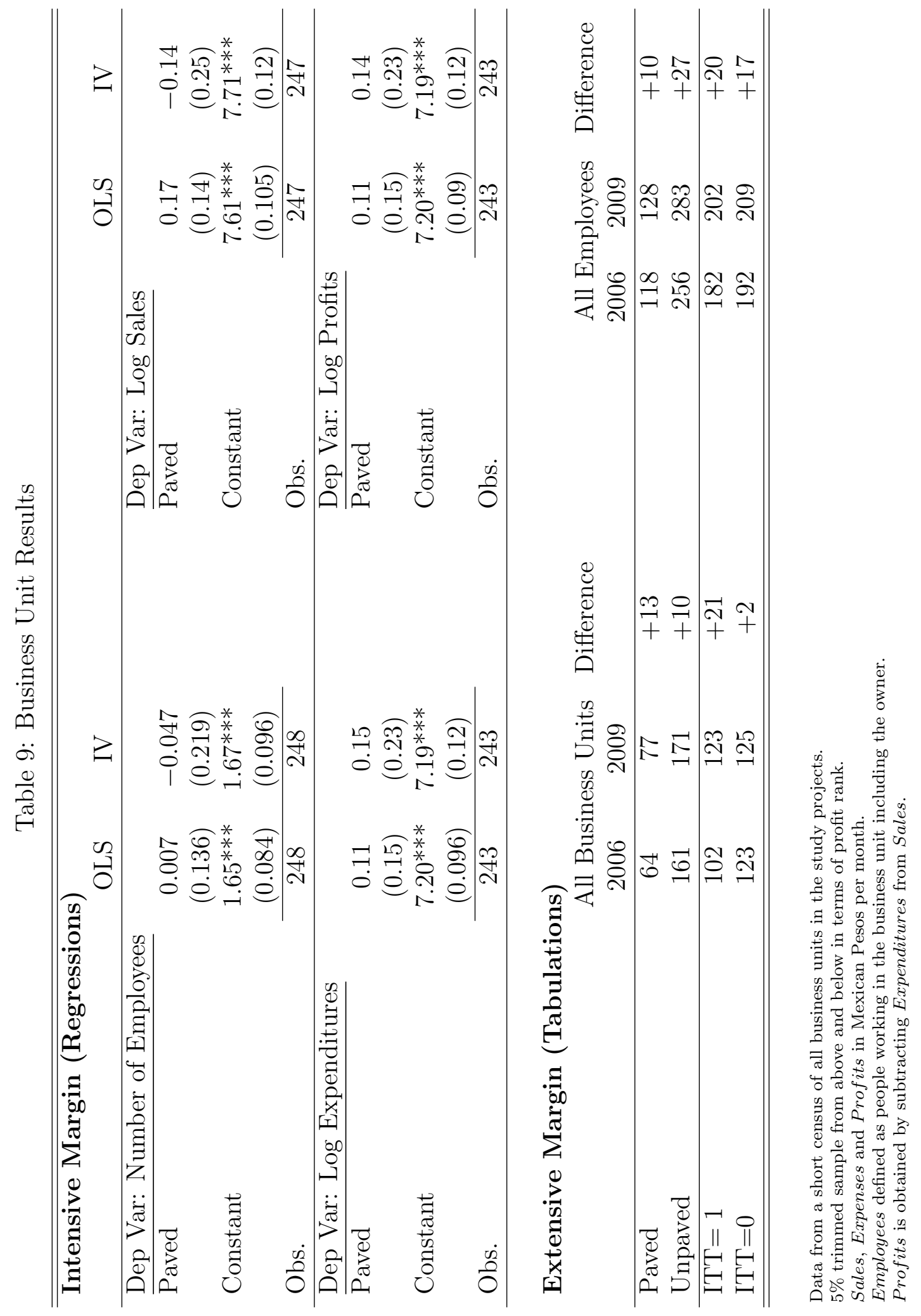


Table 10: Mechanisms

\begin{tabular}{lcccccccc}
\hline \hline & \multicolumn{2}{c}{ OLS } & \multicolumn{2}{c}{ SUR } & \multicolumn{2}{c}{ SUR } & \multicolumn{2}{c}{ SUR } \\
& $\Delta C$ & $\Delta K$ & $\Delta C$ & $\Delta K$ & $\Delta C$ & $\Delta K$ & $\Delta C$ & $\Delta K$ \\
& $(1)$ & $(2)$ & $(3)$ & $(4)$ & $(5)$ & $(6)$ & $(7)$ & $(8)$ \\
\hline$\Delta H$ & $0.0021^{* * *}$ & 0.0011 & $0.0021^{* * *}$ & 0.0011 & $0.0020^{* * *}$ & 0.0007 & $0.0020^{* * *}$ & 0.0009 \\
& $(0.0006)$ & $(0.0018)$ & $(0.0007)$ & $(0.0137)$ & $(0.0007)$ & $(0.0136)$ & $(0.0008)$ & $(0.0035)$ \\
$\Delta d$ & -6.05 & & -8.27 & & & & -16.96 & \\
& $(28.20)$ & & $(30.97)$ & & & & $(28.70)$ & \\
Constant & 62.06 & 192.56 & 60.04 & 192.56 & & & 49.18 & 30.91 \\
& $(48.13)$ & $(554.99)$ & $(44.99)$ & $(720.07)$ & & & $(48.56)$ & $(436.65)$ \\
\hline$R^{2}$ & 0.03 & 0.00 & 0.03 & 0.00 & 0.03 & 0.00 & 0.03 & 0.00 \\
Obs & 325 & 325 & 325 & 325 & 325 & 325 & 325 & 325 \\
\hline \hline
\end{tabular}

(1) and (2) are OLS weighted estimates with standard errors clustered at the street project level. (3) and (4) are SUR weighted estimates. (5) and (6) are SUR estimates constraining the constant to be 0. (7) and (8) are SUR estimates with bootstrapped standard errors.

Table 11: Cost Benefit Analysis

\begin{tabular}{|c|c|c|c|c|c|c|}
\hline & Houses & $\begin{array}{l}\text { Estimated } \\
\text { house value }\end{array}$ & $\begin{array}{l}\text { Estimated } \\
\text { impact }\end{array}$ & $\begin{array}{l}\text { Benefit per } \\
\text { dwelling }\end{array}$ & $\begin{array}{c}\text { Total } \\
\text { benefits }\end{array}$ & $\begin{array}{l}\text { Total } \\
\text { costs }\end{array}$ \\
\hline \multicolumn{7}{|l|}{$\begin{array}{l}\text { Ignoring } \\
\text { externalities }\end{array}$} \\
\hline Paved & 576 & 133,595 & 0.15 & 20,039 & $11,542,589$ & $11,304,642$ \\
\hline \multicolumn{7}{|c|}{ Rate of return: $2.1 \%$} \\
\hline \multicolumn{7}{|l|}{$\begin{array}{l}\text { Accounting for } \\
\text { externalities }\end{array}$} \\
\hline Paved & 576 & 131,311 & 0.17 & 22,323 & $12,857,984$ & $11,304,642$ \\
\hline \multirow[t]{2}{*}{ Unpaved } & 1,622 & 137,781 & 0.02 & 2,893 & $4,693,083$ & 0 \\
\hline & & & & & $17,551,067$ & $11,304,642$ \\
\hline
\end{tabular}

Rate of return: $55.3 \%$

Estimated house value uses professionally appraised house values to obtain an estimate of average property price and then corrects for program impacts. In the top panel $\frac{\hat{y}_{\text {paved }}}{(1+0.15)}$. In the lower panel $\frac{\hat{y}_{\text {paved }}}{(1+0.17)}$ and $\frac{\hat{y}_{u n p a v e d}}{(1+0.02)}$. 


\section{Appendix}

Table 12: Regression-Based Hausman Tests

\begin{tabular}{lcc}
\hline \hline & \multicolumn{2}{c}{$p$-values of equality of coefficients } \\
& OLS=IV & OLS+LO=IV+LO \\
\hline Daily hours & 0.09 & 0.12 \\
Log labor income & 0.85 & 0.50 \\
Head transportation to work & 0.93 & 0.98 \\
Plans to migrate for work reasons & 0.30 & 0.35 \\
Collateral based credit (=1) & 0.33 & 0.32 \\
Collateral based credit amount & 0.95 & 0.92 \\
Log owner estimate of house value & 0.78 & 0.69 \\
Log appraised house value & 0.48 & 0.65 \\
Bought materials for home improvement & 0.28 & 0.28 \\
Number of home improvements & 0.18 & 0.20 \\
Log per capita expenditure & 0.65 & 0.68 \\
Sum of durable goods & 0.76 & 0.64 \\
Car and truck & 0.35 & 0.80 \\
Distance to nearest paved street & 0.93 & 0.61 \\
Garbage collection & 0.03 & 0.10 \\
\hline \hline
\end{tabular}


Table 13: Impacts on Stayers (Additional outcomes)

\begin{tabular}{|c|c|c|c|c|c|}
\hline Variable & $\overline{\text { OLS }}$ & $\overline{\mathrm{O} \text { OLS+LO }}$ & $\overline{\mathrm{IV}}$ & IV+LO & Mean Control 2009 \\
\hline \multirow[t]{3}{*}{ Bathroom inside house $(=1)$} & 0.020 & 0.005 & -0.021 & 0.014 & 0.561 \\
\hline & $(0.065)$ & $(0.040)$ & $(0.092)$ & $(0.059)$ & $(0.037)$ \\
\hline & 894 & 894 & 894 & 894 & 411 \\
\hline Water connection inside & 0.057 & 0.058 & -0.027 & 0.024 & 0.522 \\
\hline \multirow{2}{*}{ house $(=1)$} & $(0.069)$ & $(0.038)$ & $(0.101)$ & $(0.056)$ & $(0.038)$ \\
\hline & 898 & 898 & 898 & 898 & 412 \\
\hline \multirow{3}{*}{ Water in lot $(=1)$} & $0.132^{* *}$ & $0.067 * *$ & 0.011 & 0.024 & 0.793 \\
\hline & $(0.063)$ & $(0.031)$ & $(0.099)$ & $(0.047)$ & $(0.035)$ \\
\hline & 898 & 898 & 898 & 898 & 412 \\
\hline \multirow{3}{*}{ Sewerage $(=1)$} & 0.041 & 0.039 & -0.019 & -0.007 & 0.930 \\
\hline & $(0.028)$ & $(0.025)$ & $(0.051)$ & $(0.042)$ & $(0.022)$ \\
\hline & 898 & 898 & 898 & 898 & 412 \\
\hline \multirow[t]{3}{*}{ Property title $(=1)$} & -0.035 & -0.024 & -0.092 & -0.063 & 0.731 \\
\hline & $(0.044)$ & $(0.037)$ & $(0.070)$ & $(0.058)$ & $(0.033)$ \\
\hline & 831 & 831 & 831 & 831 & 385 \\
\hline \multirow{3}{*}{$\begin{array}{l}\text { Cleanliness of street } \\
\text { (increasing scale }[1-5] \text { ) }\end{array}$} & $0.148 * * *$ & $0.149^{* * *}$ & $0.181^{* * *}$ & $0.185^{* * *}$ & 0.733 \\
\hline & $(0.032)$ & $(0.031)$ & $(0.056)$ & $(0.055)$ & $(0.027)$ \\
\hline & 880 & 880 & 880 & 880 & 406 \\
\hline \multirow{3}{*}{ Family and friends credit $(=1)$} & 0.003 & 0.003 & 0.002 & 0.002 & 0.004 \\
\hline & $(0.003)$ & $(0.003)$ & $(0.005)$ & $(0.005)$ & $(0.002)$ \\
\hline & 1,984 & 1,984 & 1,984 & 1,984 & 937 \\
\hline \multirow{3}{*}{ Informal private credit $(=1)$} & -0.001 & -0.001 & 0.001 & 0.001 & 0.002 \\
\hline & $(0.002)$ & $(0.002)$ & $(0.003)$ & $(0.003)$ & $(0.002)$ \\
\hline & 1,984 & 1,984 & 1,984 & 1,984 & 937 \\
\hline Collateral-based credit amount & 6,000 & 5,613 & $10,485^{*}$ & $9,868^{*}$ & 7,274 \\
\hline \multirow{2}{*}{ | CB-credit $>0$ in 06 or 09} & $(4,990)$ & $(4,533)$ & $(5,935)$ & $(5,542)$ & $(1,494)$ \\
\hline & 329 & 1,984 & 1,984 & 1,984 & 143 \\
\hline \multirow[t]{3}{*}{ Credit amount } & 1,533 & 1,297 & $2,360^{*}$ & $2,023^{*}$ & 1,103 \\
\hline & $(1,099)$ & $(889)$ & $(1,299)$ & $(1,081)$ & $(231)$ \\
\hline & 1,984 & 1,984 & 1,984 & 1,984 & 937 \\
\hline \multirow{3}{*}{$\begin{array}{l}\text { Credit amount } \\
\mid \text { credit }>0 \text { in } 06 \text { or } 09\end{array}$} & 6,000 & 5,613 & $10,485^{*}$ & $9,868^{*}$ & 7,274 \\
\hline & $(4,990)$ & $(4,533)$ & $(5,935)$ & $(5,542)$ & $(1,494)$ \\
\hline & 329 & 329 & 329 & 329 & 143 \\
\hline \multirow{3}{*}{$\begin{array}{l}\text { Satisfaction living in city } \\
\text { (increasing scale }[1-4] \text { ) }\end{array}$} & 0.007 & 0.008 & 0.005 & 0.006 & 3.14 \\
\hline & $(0.043)$ & $(0.043)$ & $(0.056)$ & $(0.056)$ & $(0.023)$ \\
\hline & 897 & 897 & 897 & 897 & 412 \\
\hline \multirow[t]{3}{*}{ Business opening last year $(=1)$} & 0.021 & 0.021 & 0.039 & 0.039 & 0.040 \\
\hline & $(0.018)$ & $(0.018)$ & $(0.026)$ & $(0.026)$ & $(0.010)$ \\
\hline & 897 & 897 & 897 & 897 & 411 \\
\hline \multirow{3}{*}{ Garbage collection $(=1)$} & $0.134^{*}$ & $0.118^{* *}$ & -0.020 & 0.024 & 0.707 \\
\hline & $(0.076)$ & $(0.055)$ & $(0.121)$ & $(0.087)$ & $(0.053)$ \\
\hline & 899 & 899 & 899 & 899 & 413 \\
\hline \multirow[t]{3}{*}{ Gas delivery $(=1)$} & $0.088^{* * *}$ & 0.053 & -0.025 & -0.051 & 0.940 \\
\hline & $(0.023)$ & $(0.016)$ & $(0.057)$ & $(0.043)$ & $(0.024)$ \\
\hline & 898 & 898 & 898 & 898 & 411 \\
\hline \multirow[t]{3}{*}{ Cost of taxi to city center } & -1.57 & $-0.985^{* *}$ & -0.198 & -0.580 & 18.14 \\
\hline & $(1.03)$ & $(0.483)$ & $(1.67)$ & $(0.765)$ & $(0.697)$ \\
\hline & 889 & 889 & 889 & 889 & 407 \\
\hline \multirow[t]{3}{*}{ Feel safe walking in street $(=1)$} & $0.120 * *$ & $0.103^{* *}$ & 0.050 & 0.047 & 0.623 \\
\hline & $(0.046)$ & $(0.482)$ & $(0.071)$ & $(0.066)$ & $(0.028)$ \\
\hline & 888 & 888 & 888 & 888 & 410 \\
\hline
\end{tabular}

IV uses intent to treat assignment as the instrumental variable for getting road pavement. $L O$ stands for lagged outcome included as regressor. Regressions use survey weights and standard errors clustered at the street project level.

Water in lot $=1$ if property has running water service, but not necessarily inside the house.

House flooding $=1$ if house has suffered from flooding in the past year.

Cost of taxi in 2009 Mexican pesos. 